\title{
Strategies for Design of Potential Singlet Fission Chromophores Utilizing a Combination of Ground-State and Excited-State Aromaticity Rules
}

\author{
Ouissam El Bakouri, Joshua R. Smith, and Henrik Ottosson*
}

Cite This: J. Am. Chem. Soc. 2020, 142, 5602-5617

Read Online

ACCESS | Lلll Metrics \& More | 国 Article Recommendations ｜ sl Supporting Information

ABSTRACT: Singlet exciton fission photovoltaic technology requires chromophores with their lowest excited states arranged so that $2 E\left(\mathrm{~T}_{1}\right)<$ $E\left(\mathrm{~S}_{1}\right)$ and $E\left(\mathrm{~S}_{1}\right)<E\left(\mathrm{~T}_{2}\right)$. Herein, qualitative theory and quantum chemical calculations are used to develop explicit strategies on how to use Baird's $4 n$ rule on excited-state aromaticity, combined with Hückel's $4 n+2$ rule for ground-state aromaticity, to tailor new potential chromophores for singlet fission. We first analyze the $E\left(\mathrm{~T}_{1}\right), E\left(\mathrm{~S}_{1}\right)$, and $E\left(\mathrm{~T}_{2}\right)$ of benzene and cyclobutadiene (CBD) as excited-state antiaromatic and aromatic archetypes, respectively, and reveal that $\mathrm{CBD}$ fulfills the criteria on the state ordering for a singlet fission chromophore. We then look at fulvenes, a class of compounds that can be tuned by choice of substituents from Bairdantiaromatic to Baird-aromatic in $T_{1}$ and $S_{1}$ and from Hückel-aromatic to Hückel-antiaromatic in $S_{0}$. The $T_{1}$ and $S_{1}$ states of most substituted fulvenes

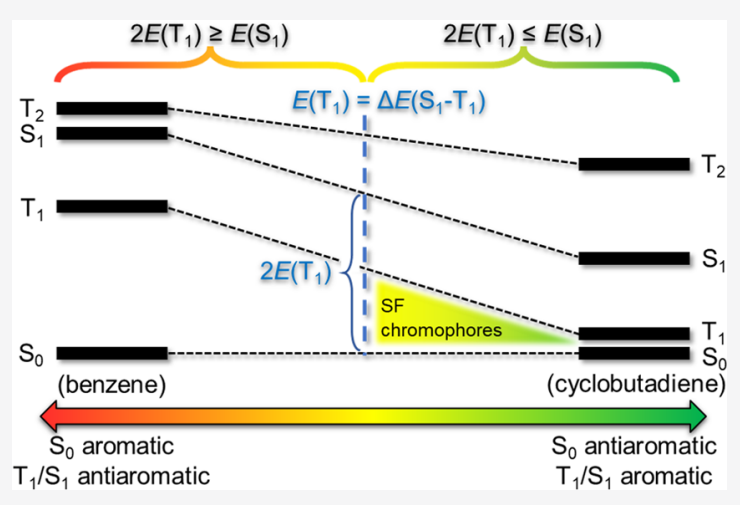
(159 of 225) are described by singly excited HOMO $\rightarrow$ LUMO configurations, providing a rational for the simultaneous tuning of $E\left(\mathrm{~T}_{1}\right)$ and $E\left(\mathrm{~S}_{1}\right)$ along an approximate (anti)aromaticity coordinate. Key to the tunability is the exchange integral $\left(K_{\mathrm{H}, \mathrm{L}}\right)$, which ideally is constant throughout the compound class, providing a constant $\Delta E\left(\mathrm{~S}_{1}-\mathrm{T}_{1}\right)$. This leads us to a geometric model for the identification of singlet fission chromophores, and we explore what factors limit the model. Candidates with calculated $E\left(\mathrm{~T}_{1}\right)$ values of $\sim 1 \mathrm{eV}$ or higher are identified among benzannelated $4 n \pi$ electron compound classes and siloles. In brief, it is clarified how the joint utilization of Baird's $4 n$ and Hückel's $4 n+2$ rules, together with substituent effects (electronic and steric) and benzannelation, can be used to tailor new chromophores with potential use in singlet fission photovoltaics.

\section{INTRODUCTION}

Research on solar energy harvesting is one of the most active areas within chemistry, and photovoltaics technology is one of the main directions for turning solar energy into electricity. Today, three different generations of photovoltaics exist. ${ }^{1,2}$ The third and most recent generation includes materials able to overcome the Shockley-Queisser limit $(\sim 33 \%) .3,4$ This generation includes singlet exciton fission photovoltaics, or shortly singlet fission, i.e., a process where one photon of light, absorbed by a molecule, is used to create two excitons of triplet multiplicity in two molecules or in two chromophores linked intramolecularly. 5

In singlet fission, a molecule in its first singlet excited-state $\left(S_{1}\right)$ kickbacks some of its energy, transferring it to a neighboring ground-state $\left(S_{0}\right)$ molecule, and both end up in the lowest triplet state $\left(\mathrm{T}_{1}\right)$. For this process, one needs molecules with their lowest excited states arranged according to at least two key criteria: the $S_{1}$ state and second triplet excited $\left(\mathrm{T}_{2}\right)$-state should have energies higher than twice that of the $\mathrm{T}_{1}$ state, i.e., $2 E\left(\mathrm{~T}_{1}\right)<E\left(\mathrm{~S}_{1}\right)$ and $2 E\left(\mathrm{~T}_{1}\right)<E\left(\mathrm{~T}_{2}\right)$. The first criterion guarantees that the singlet fission is exergonic and the second that the $\mathrm{T}_{1}+\mathrm{T}_{1} \rightarrow \mathrm{T}_{2}$ annihilation is slow and endergonic. ${ }^{5-7}$ Ideally, $E\left(S_{1}\right)$ should also lie $0.1-0.2 \mathrm{eV}$ above $2 E\left(T_{1}\right)$. Desirably, the $T_{2}$ state should be at an energy higher than the $S_{1}$ state, i.e., $E\left(S_{1}\right)<E\left(T_{2}\right)$, so as to hamper intersystem crossing from $S_{1}$ to $T_{2}{ }^{8}$. Combined, this means that $2 E\left(\mathrm{~T}_{1}\right)<E\left(\mathrm{~S}_{1}\right)<E\left(\mathrm{~T}_{2}\right)$ for a singlet fission chromophore. Finally, to maximize the efficiency in energy conversion, $E\left(T_{1}\right)$ should preferably be close to or slightly above $1 \mathrm{eV}$ as this facilitates triplet exciton transfer and charge injection from the molecule into a silicon electrode, which has a bandgap of 1.11 eV. ${ }^{9}$ Such a process was recently accomplished by tetracene $\left(E\left(\mathrm{~T}_{1}\right)=1.25 \mathrm{eV}\right)$, enabling a combined exciton yield of $133 \%$ $\pm 13 \% .{ }^{10}$ This and several other recent studies reveal that efficient combinations of singlet exciton fission with semi-

Received: November 18, 2019

Published: February 28, 2020 
conductor technology can be accomplished to achieve triplet exciton harvesting and charge injection into electrodes, inducing photocurrents. ${ }^{11-15}$

A number of aspects need to be taken into account for the enhanced design of singlet fission solar cells. ${ }^{16-18}$ We need, for example, deepened mechanistic understanding of the exciton fission process, better control of intra- and intermolecular singlet fission rates, and improved understanding of how singlet fission chromophores interact with each other as well as with a semiconductor surface or quantum dot. To fit many different technological setups we should also compose a library of compounds that expands outside the acenes suitable for singlet fission, and chromophores with higher $E\left(\mathrm{~T}_{1}\right)$ than the present ones should be identified. ${ }^{17,18}$ However, how can further chromophores with the desired characteristics be discovered?

The search for materials suitable for singlet fission is not a straightforward task, particularly as the experimental determination of $E\left(T_{1}\right)$ is less facile than for $E\left(S_{1}\right)$. However, with the help of quantum chemical analyses, the search has evolved considerably over the last years. ${ }^{8,19-27}$ The first experimental evidence of efficient singlet fission was observed for anthracene crystals, and research then expanded to tetracene and pentacene materials. ${ }^{28-30}$ 1,3-Diphenylisobenzofuran (DPB) was the first compound observed to undergo singlet fission that had been predicted by theoretical modeling. ${ }^{31,32}$

Recently, Bronstein, Musser, Friend, and co-workers used for the first time the concept of $\mathrm{T}_{1}$-state Baird-aromaticity ${ }^{33-36}$ to analyze singlet fission chromophores. ${ }^{37}$ They studied indolonaphthyridine thiophene (INDT) derivatives, which they described as influenced by a resonance structure with a $4 \pi$-electron Baird-aromatic cycle. On the basis of quantum chemical computations of nearly 10000 INDT derivatives, they concluded that a significant part of these are influenced by aromaticity to various extents in their $T_{1}$ states and have the appropriate relative arrangement of $E\left(\mathrm{~T}_{1}\right)$ and $E\left(\mathrm{~S}_{1}\right)$ to function in singlet fission photovoltaics. Significantly higher photostabilities of two INDT derivatives compared to TIPSpentacene were also observed, ${ }^{37}$ a feature of excited-state aromatic molecules with $4 n \pi$-electron cycles earlier noted by Wan and Shukla for dibenz $[b, f]$ oxepins. ${ }^{38,39}$

Now, what are the explicit scopes of $T_{1}$-state Bairdaromaticity for the design of singlet fission chromophores, and what are the limitations? It was argued by Ryerson et al., ${ }^{40}$ when analyzing the INDT compounds by Fallon et al., ${ }^{37}$ that the intermediate triplet-state aromaticity yielding the $E\left(S_{1}\right)=$ $2 E\left(T_{1}\right)$ situation needs to be found through inspection of calculated adiabatic excitation energies. Thus, a qualitative tool should be desirable. Herein, we report on approaches for the correlated tuning of the $E\left(\mathrm{~T}_{1}\right)$ and $E\left(\mathrm{~S}_{1}\right)$ of Baird-aromatic chromophores by exploiting an earlier observed similarity in the electronic structures of the $T_{1}$ and $S_{1}$ states of Bairdaromatic molecules. ${ }^{39,41}$ Are their ways by which $E\left(\mathrm{~T}_{1}\right)$ and $E\left(S_{1}\right)$ can be tuned predictably in a similar manner while $E\left(\mathrm{~T}_{2}\right)$ is left unaffected or changes in another way than $E\left(\mathrm{~T}_{1}\right)$ and $E\left(\mathrm{~S}_{1}\right)$ ? How are compounds with $E\left(\mathrm{~T}_{1}\right)$ slightly above 1 $\mathrm{eV}$ identified, allowing for the combination of the singlet fission process with existing silicon solar cell technology? We develop a general design strategy by combining qualitative theory on excited-state Baird- and ground-state Hückelaromaticity with quantum chemical computations. We arrive at approaches that could be applied broadly to identify a plethora of excited-state Baird-aromatic compounds and compound classes potentially suitable for singlet fission photovoltaics.

Design Strategies. Molecules with Baird-aromatic $T_{1}$ states in general have a low $E\left(\mathrm{~T}_{1}\right)$, as the aromatic character leads to a stabilization of that state relative to the $S_{0}$ state, which is Hückel anti- or nonaromatic. ${ }^{35,39,41}$ Cyclobutadiene (CBD), which is $\mathrm{T}_{1}$-state Baird-aromatic, fulfills the first criterion as $E\left(\mathrm{~S}_{1}\right) / E\left(\mathrm{~T}_{1}\right)=2.84 .^{42}$ The opposite applies to benzene $\left(\mathrm{T}_{1}\right.$-state Baird-antiaromatic) because $E\left(\mathrm{~S}_{1}\right) / E\left(\mathrm{~T}_{1}\right)=$ 1.35. ${ }^{43}$ Thus, one should search for (moderately) Bairdaromatic compounds with $E\left(\mathrm{~T}_{1}\right)$ that are approximately double the $E\left(\mathrm{~T}_{1}\right)$ of CBD $(0.59 \mathrm{eV})^{42}$ to achieve an $E\left(\mathrm{~T}_{1}\right)$ similar to the band gap of silicon $(1.11 \mathrm{eV})$. If one can identify compound classes influenced by Baird-aromaticity and throughout which the $S_{1}$ and $T_{1}$ states are described by the same HOMO $\rightarrow$ LUMO singly excited electron configuration (except for a spin-flip), it should be possible to find specific compounds that fit the requirements. In such compound classes, the absolute changes in $E\left(\mathrm{~T}_{1}\right)$ and $E\left(\mathrm{~S}_{1}\right)$ should be similarly large because the two states will be influenced in the same manner by, for example, electronic or steric effects caused by substituents. Throughout the compound class, the energy difference between the two states will then equal twice the exchange integral, i.e., $\Delta E\left(S_{1}-T_{1}\right)=2 K_{\mathrm{ij}}=2 K_{\mathrm{H}, \mathrm{L}}(i$ and $j=$ orbitals involved in excitation, $\mathrm{H}=\mathrm{HOMO}$ and $\mathrm{L}=\mathrm{LUMO}$ ).

Now, if the $E\left(\mathrm{~T}_{1}\right)$ and $E\left(\mathrm{~S}_{1}\right)$ of the various specific compounds in the compound class are plotted against an (anti)aromaticity index ( $\sim$ coordinate), one can tentatively determine a threshold degree of (anti)aromaticity between the compounds that satisfy the singlet fission criterion and those that do not (Figure 1). At that threshold, $E\left(S_{1}\right)$ will equal twice

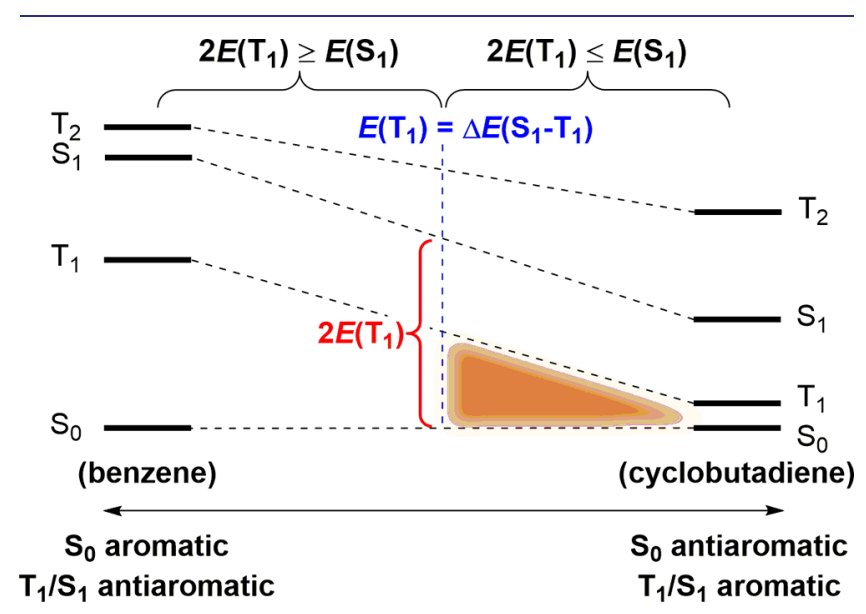

Figure 1. Desired arrangement of the lowest electronic states within a particular compound class that encompasses both $S_{0}$ aromatic $\left(T_{1} / S_{1}\right.$ antiaromatic) compounds and $S_{0}$ antiaromatic $\left(T_{1} / S_{1}\right.$ aromatic) compounds. Compounds within the orange region have $2 E\left(T_{1}\right)<$ $E\left(\mathrm{~S}_{1}\right)$.

$E\left(T_{1}\right)$, and potential singlet fission chromophores will be found on the right side of the threshold (orange region in Figure 1). However, the hypothesis summarized in Figure 1 assumes that $2 K_{\mathrm{H}, \mathrm{L}}$ is constant over the interval, but even if HOMO and LUMO keep their respective symmetries throughout a compound class, their spatial localization may shift; as a result, $2 K_{\mathrm{H}, \mathrm{L}}$ will change in size. The importance of colocalization of the HOMO and LUMO to the same atoms for a large $2 K_{\mathrm{H}, \mathrm{L}}$ becomes clear through a comparison of naphthalene with azulene: naphthalene with a HOMO and 
A
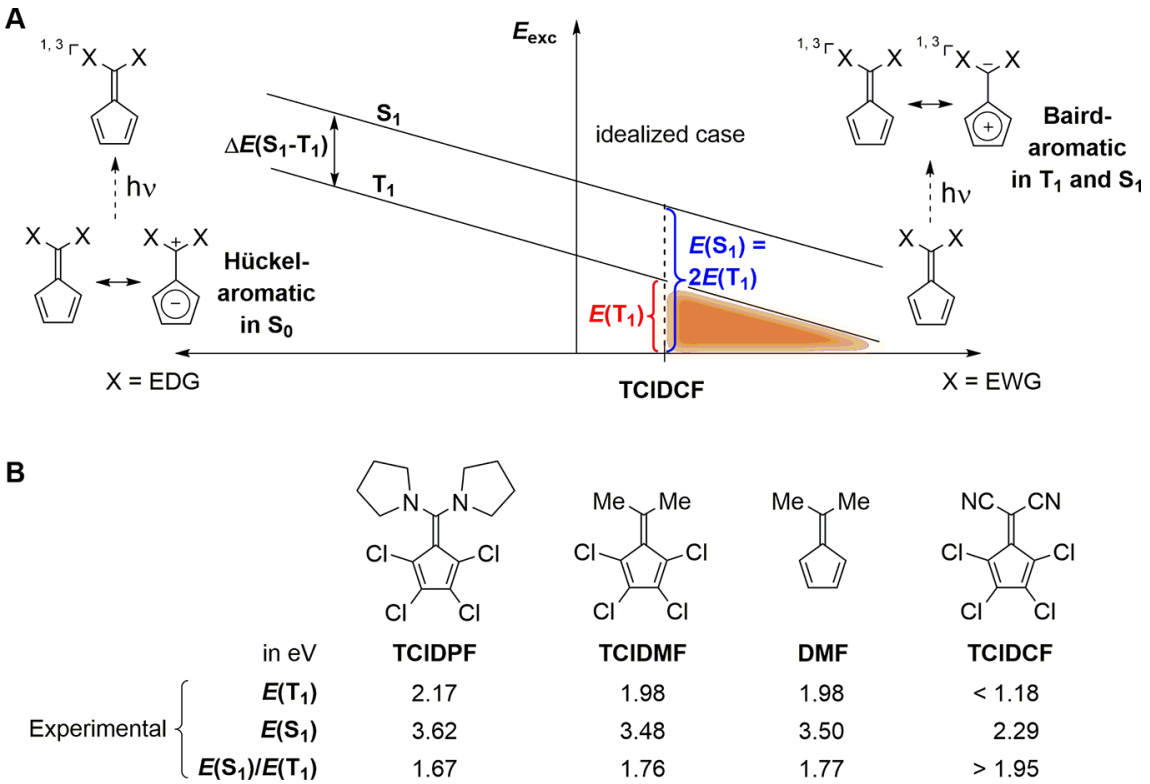

Figure 2. (A) Postulated (idealized) variation in excitation energies of fulvenes as one goes from electron donating groups (EDGs) to electron withdrawing groups (EWGs). The figure displays the ideally constant energy difference between $E\left(\mathrm{~T}_{1}\right)$ and $E\left(\mathrm{~S}_{1}\right)\left(\Delta E\left(\mathrm{~S}_{1}-\mathrm{T}_{1}\right)=2 K_{i j}\right)$, upon which our hypothesis is based. (B) $E\left(\mathrm{~S}_{1}\right) / E\left(\mathrm{~T}_{1}\right)$ ratio for four experimentally investigated fulvene derivatives, i.e., TCIDCF, TClDMF, DMF, and TClDPF (see refs 46 and 47).

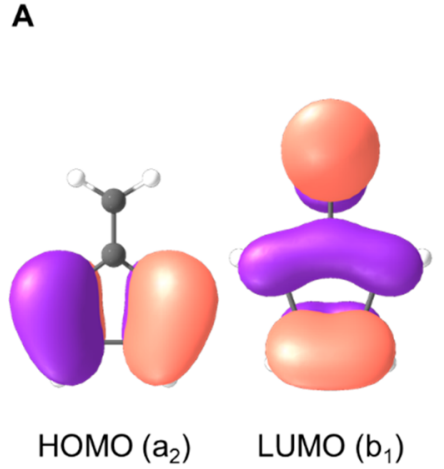

$\operatorname{HOMO}\left(\mathrm{a}_{2}\right) \quad$ LUMO $\left(\mathrm{b}_{1}\right)$

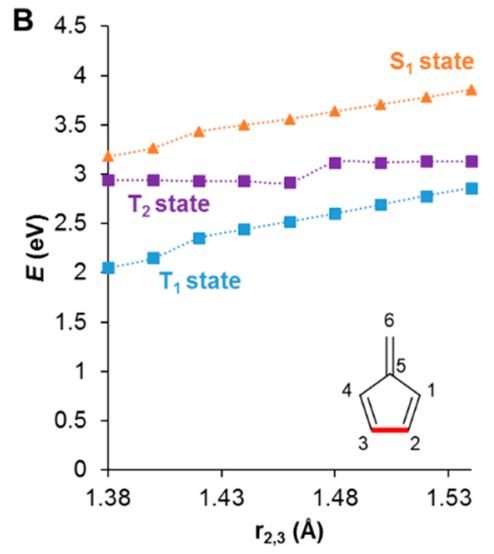

Figure 3. (A) Plots of HOMO and LUMO of the parent fulvene, and (B) two plots showing how $E\left(\mathrm{~T}_{1}\right)_{\mathrm{v}}, E\left(\mathrm{~S}_{1}\right)_{\mathrm{v}}$, and $E\left(\mathrm{~T}_{2}\right)_{\mathrm{v}}$ vary as functions of the $\mathrm{CC}$ bond lengths marked in red. Calculations at TD-M06-2X/6-311+G(d,p) level.

LUMO colocalized to the same atoms has an $\Delta E\left(\mathrm{~S}_{1}-\mathrm{T}_{1}\right)$ of $1.7 \mathrm{eV}$, while azulene, where the HOMO and LUMO are not fully colocalized and somewhat polarized toward different ends of the molecule, has an $\Delta E\left(\mathrm{~S}_{1}-\mathrm{T}_{1}\right)$ of $0.5 \mathrm{eV} .^{44}$ Similarly, the $\Delta E\left(\mathrm{~S}_{1}-\mathrm{T}_{1}\right)$ of individual compounds within a compound class will vary if there is a change in the spatial distribution of $\mathrm{HOMO}$ and/or LUMO throughout the class.

We first test our design strategy on substituted fulvenes (pentafulvenes) being a compound class with $E\left(\mathrm{~T}_{1}\right)$ and $E\left(\mathrm{~S}_{1}\right)$ that span a large part of the region between the corresponding excited-state energies of benzene and CBD. ${ }^{45-49}$ This feature is a result of the "aromatic chameleon" character of fulvenes, meaning that they can adapt to the different aromaticity rules in different electronic states: Baird's rule in $T_{1}$ and $S_{1}$ and Hückel's rule in $S_{0}{ }^{50} \pi$-Electron withdrawing groups (EWGs) at the exocyclic position lead to low-lying $T_{1}$ and $S_{1}$ states, as they enhance the Baird-aromatic character of these states (Figure 2A). Computations have shown that fulvenes and related compounds with triplet ground $\left(\mathrm{T}_{0}\right)$ states are possible, ${ }^{50,51}$ explained by the fact that the cyclopentadienyl cation $\left(\mathrm{Cp}^{+}\right)$has a triplet ground state. ${ }^{52-54}$ Assuming that the $\mathrm{T}_{1}$ and $\mathrm{S}_{1}$ states are described by the same electron configuration, except for the multiplicity difference, this means that a particular EWG at the exocyclic position of a fulvene will have the same stabilizing effect in $S_{1}$ as in $T_{1}$ when compared to the parent fulvene as a reference.

Indeed, the tunability of $E\left(\mathrm{~T}_{1}\right)$ and $E\left(\mathrm{~S}_{1}\right)$ was earlier observed experimentally for four fulvene derivatives: $1,2,3,4-$ tetrachloro-6,6-dipyrrolidinofulvene (TCIDPF), 1,2,3,4-tetrachloro-6,6-dimethylfulvene (TClDMF), 1,2,3,4-tetrachloro6,6-dicyanofulvene (TClDCF), and 6,6-dimethylfulvene (DMF) (Figure 2B). ${ }^{45,46}$ For singlet fission, it is rewarding that the experimental $E\left(S_{1}\right) / E\left(T_{1}\right)$ ratio increases when going from TClDPF to TClDCF (Figure $2 \mathrm{~B}$ ) so that $E\left(\mathrm{~S}_{1}\right)$ in TCIDCF is (at least) nearly twice larger than $E\left(T_{1}\right)$. With TCIDCF being a stable organic compound, together with the recently reported INDT derivatives, ${ }^{37}$ it is revealed that a large number of chromophores, which to various extents are 
influenced by aromaticity in their $\mathrm{T}_{1}$ states, are awaiting to be discovered and used in singlet fission photovoltaics. In fact, the experimental $\Delta E\left(S_{1}-T_{1}\right)$ values for the four fulvenes displayed in Figure $2 \mathrm{~B}$ are similar for three compounds (TCIDPF, TCIDMF, and DMF) yet are possibly higher for TCIDCF, as only an upper limit of $E\left(\mathrm{~T}_{1}\right)$ was assessed for the latter compound $(1.45,1.50,1.52$, and $<1.11 \mathrm{eV}$, respectively). The experimental $E\left(\mathrm{~S}_{1}\right) / E\left(\mathrm{~T}_{1}\right)$ ratio of TClDCF, which is 1.95 or higher, suggests that this compound may indeed function as a singlet fission chromophore.

The design strategy outlined for fulvenes in Figure 2A utilizes electronic substituent effects, but altered steric congestion can also change $E\left(\mathrm{~T}_{1}\right)$ and $E\left(\mathrm{~S}_{1}\right)$. Again, this effect can be exemplified on fulvenes by altering the $\mathrm{CC}$ bond lengths in silico. This modulates the energies of the HOMO and LUMO (Figure 3A) by changing the strength of either the bonding or the antibonding character of an orbital at a particular bond. If the $T_{1}$ and $S_{1}$ states are HOMO $\rightarrow$ LUMO single excitations, this allows for tuning of the $E\left(\mathrm{~T}_{1}\right)$ and $E\left(S_{1}\right)$. As seen for the parent fulvene (Figure $3 \mathrm{~B}$ ), the relevant states change in energy as a function of $\mathrm{CC}$ bond lengths, and the absolute energy changes for the $T_{1}$ and $S_{1}$ states in each of the two types of distortions. Specifically, the energies of the two states decrease by 0.81 and $0.68 \mathrm{eV}$ when the $r_{2,3}$ bond is shortened from 1.54 to $1.38 \AA$, and they decrease in energy by 0.98 and $0.86 \mathrm{eV}$ when the $r_{1,2}=r_{3,4}$ distances are elongated from 1.35 to $1.45 \AA$. Thus, $\Delta E\left(S_{1}-\mathrm{T}_{1}\right)$ remains rather constant if there is no gradual shift in the location of the HOMO relative to the LUMO along the distortion coordinate. The $\mathrm{T}_{2}$ state in the distorted parent fulvene, on the other hand, displays smaller changes ( 0.19 and $0.48 \mathrm{eV}$, respectively). Indeed, molecular contortion (bending and twisting) has recently been shown to be one means for altering $E\left(\mathrm{~T}_{1}\right)$ and $E\left(S_{1}\right)$ so as to improve singlet fission performance of an existing chromophore. ${ }^{55}$

A further design approach is to combine Baird's rule with Clar's rule, ${ }^{56-58}$ as that particular isomer among a series of isomeric polycyclic antiaromatic hydrocarbons (PAAHs) that maximizes the total number of aromatic monocycles in the $T_{1}$ state (one Baird $\pi$-quartet or $\pi$-octet plus Clar $\pi$-sextets) has the lowest $E\left(\mathrm{~T}_{1}\right)$ value. $^{59}$ By selecting the proper isomer, it should be possible to identify the $\mathrm{T}_{1}$-state Baird-aromatic compounds with $E\left(\mathrm{~T}_{1}\right)=1.1-1.2 \mathrm{eV}$, which fulfill the singlet fission criteria. However, it is important to note that the isomer, which is ideal for singlet fission, is not necessarily the one that is the most strongly Baird-aromatic in its $\mathrm{T}_{1}$ state, as also concluded by Ryerson et al. ${ }^{40}$ Another more established approach for the design of singlet fission chromophores is the diradical character-based design. ${ }^{6,20,24,26,60-62}$ It has been found that molecules with the proper amount of open-shell singlet diradical character often satisfy the singlet fission criteria, ${ }^{26,63}$ and a connection between the diradical character and aromaticity has been described for heteroacenes. ${ }^{24} \mathrm{~A}$ link to our approach based on Baird-aromaticity can likely be formulated, yet the extent of diradical character in the $S_{0}$ state may not necessarily reflect Baird-aromaticity in the $T_{1}$ state (vide infra).

Finally, it should be noted that our design strategies are approaches for identification of candidate chromophores for singlet fission. The strategies do not take into consideration, for example, nonradiative decay processes from the $S_{1}$ state to the $S_{0}$ state. Indeed, it has earlier been observed that some $4 n \pi$-electron compounds can have very short excited-state lifetimes (less than $1 \mathrm{~ns}$ ), ${ }^{64}$ a feature that could limit the applicability of Baird-aromatic chromophores in singlet fission photovoltaics. We calculated spin-orbit coupling (SOC) elements as a means to determine the probability for intersystem crossings; however, photophysical processes that are limiting for singlet fission performance are likely best probed experimentally. Thus, further careful design is needed, for example, to constrain the molecules into rigid frameworks, hampering the geometric distortions that open pathways for nonradiative decay.

\section{RESULTS AND DISCUSSION}

The validity of the design strategy is first examined on fulvenes (pentafulvenes), as they represent a compound class in which the (anti)aromatic character of both the $S_{0}$ state and the $T_{1}$ and $S_{1}$ states can be varied extensively. ${ }^{45-49}$ Our computations were mostly run with DFT at (U)M06-2X and TD-M06-2X levels, ${ }^{65}$ but CASPT2//CASSCF multireference computations were also performed. ${ }^{66} \mathrm{We}$ primarily used a computational scheme derived by Zeng, Hoffmann, and Ananth (ZHA), which uses adiabatic excitations to the $T_{1}$ state and vertical excitations to the $S_{1}\left(T_{2}\right)$ states from the $S_{0}\left(T_{1}\right)$ optimized structures. This approach gives the correct ordering of the $T_{1}$, $S_{1}$, and $T_{2}$ states of pentacene, ${ }^{67}$ and it gives the $E\left(S_{1}\right) / E\left(T_{1}\right)$ ratios for pentacene and $\mathrm{DPB}$ above or close to 2 (2.33 and 1.96 with M06-2X, see Table S1). However, at times, we also used either (i) vertically excited $E\left(\mathrm{~T}_{1}\right)$, labeled as $E\left(\mathrm{~T}_{1}\right)_{\mathrm{v}}$ as opposed to the adiabatic ones labeled $E\left(\mathrm{~T}_{1}\right)_{\mathrm{a}}$, or (ii) adiabatically excited $E\left(S_{1}\right)$ labeled as $E\left(S_{1}\right)_{a}$. When evaluated against the experimental $E\left(\mathrm{~T}_{1}\right)$ and $E\left(S_{1}\right)$ of pentacene, tetracene, DPB, and the four fulvenes of Figure 2, it becomes clear that the approach with vertical $E\left(\mathrm{~T}_{1}\right)$ and $E\left(S_{1}\right)$ underestimates $E\left(S_{1}\right) / E\left(T_{1}\right)$ when compared to experiments while the ZHA approach exaggerates the ratio. The extent of geometric relaxation in the $S_{1}$ versus $T_{1}$ states is important to take into consideration, as this varies between the compound classes.

Kaupp and co-workers previously used a TD-DFT-based protocol for the screening of singlet fission chromophores and, provided there is no evidence of multireference character, they proposed vertical excitation energies computed with local hybrid functionals. ${ }^{68}$ However, M06-2X was found to perform similarly. For the $T_{1}$ energies and optimized geometries of substituted fulvenes, we recently observed a good agreement between CASPT2 and M06-2X, ${ }^{49}$ and we therefore used (U)M06-2X. For method assessments on CBD, benzene, DPB, and pentacene, see the Supporting Information. In short, the $\mathrm{T}_{1^{-}}, \mathrm{S}_{1^{-}}$, and $\mathrm{T}_{2}$-state orderings are the same with (TD-)M06$2 \mathrm{X}$ and CASPT2, and the $E\left(\mathrm{~S}_{1}\right)_{\mathrm{v}} / E\left(\mathrm{~T}_{1}\right)_{\mathrm{a}}$ with the two methods using the ZHA scheme resemble each other. The (anti)aromatic character of fulvenes was determined through nucleus-independent chemical shifts $(\mathrm{NICS})^{69,70}$ computed with the GIAO method ${ }^{71}$ in the $S_{0}$ and $T_{1}$ states at optimized geometries. NICS calculations in the $S_{1}$ state are cumbersome, and we instead used the electronic multicenter index $(\mathrm{MCI})^{72}$ for selected compounds. The geometry-based HOMA index $^{73,74}$ is not ideal for small $\mathrm{T}_{1}$ aromatic molecules (HOMA equals 0.73 for ${ }^{3} \mathrm{Cp}^{+}$and 0.45 for ${ }^{3} \mathrm{CBD}$, thus not reflecting the aromatic ideal of 1.0), and we avoid it for the fulvenes. In contrast, HOMA was used to assess the aromaticity of individual $4 n \pi$-electrons rings of polycyclic compounds as the extent of aromaticity of individual rings in 
such systems cannot be determined by NICS as each ring is influenced by several diatropic or paratropic circuits.

Design Strategy Tested on Substituted Model Fulvenes. As pointed out by Zeng et al., ${ }^{25}$ the parent fulvene cannot be used for singlet fission applications since it has a low-lying $T_{2}$ state, and it also undergoes efficient $S_{1} / S_{0}$ radiationless decay via two possible conical intersections (one planar and one twisted). ${ }^{75,76}$ As seen below, the first of the two drawbacks is overcome by utilizing electronic substituent effects. The second drawback can likely be alleviated by benzannelation, leading to a rigidification of the molecular structure. We explored fulvenes substituted at the exocyclic 6-position (substituents X, Figure 4) and/or at the

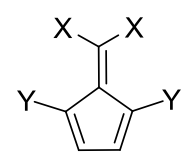

$\mathrm{X}, \mathrm{Y}=\mathrm{NMe}_{2}, \mathrm{NH}_{2}, \mathrm{OH}, \mathrm{OMe}, \mathrm{SH}, \mathrm{Me}$, $\mathrm{SiH}_{3}, \mathrm{H}, \mathrm{BH}_{2}, \mathrm{BF}_{2}, \mathrm{~F}, \mathrm{Cl}, \mathrm{CF}_{3}, \mathrm{CN}, \mathrm{NO}_{2}$

Figure 4. Di- and tetrasubstituted fulvene derivatives included in this work.

endocyclic 2- and 5-positions (substituents Y). The substituents $\mathrm{X}$ and $\mathrm{Y}$ were selected as electron neutral, electron donating, and electron withdrawing. With the chosen substituents, we span fulvenes with calculated $E\left(\mathrm{~T}_{1}\right)_{\mathrm{a}}$ in the range $0.10-2.81 \mathrm{eV}$. We did not consider fulvenes substituted at the 3-and 4-positions because substituents at these positions have only weak electronic impact due to steric hindrance, which twists the substituents out of conjugation with the 5membered ring. ${ }^{49}$ It should also be emphasized that the fulvenes of Figure 4 are model compounds (many are experimentally unrealistic) that allow us to explore the design hypothesis of Figures 1 and 2A. The initial set included 225 fulvenes, but 2 had triplet ground states $\left(T_{0}\right), 15$ rearranged to an isomeric compound in the $S_{0}$ and/or $T_{1}$ state, and 49 had a HOMO and/or LUMO not analogous to those of the parent fulvene. These 66 were not further analyzed, whereby the set included 159 fulvenes (Table S2), i.e., 71\% of the initial set.

Throughout the fulvenes with the $T_{1}$ and $S_{1}$ states described as singly excited HOMO $\rightarrow$ LUMO excitations, there are still complications. This is exemplified through two fulvenes that represent limiting cases with, respectively, high and low $E\left(\mathrm{~T}_{1}\right)$ and $E\left(S_{1}\right)$ values (Figure $S 1$ ). The first fulvene with $\mathrm{X}=\mathrm{NH}_{2}$ and $\mathrm{Y}=\mathrm{CN}$ has $E\left(\mathrm{~T}_{1}\right)_{\mathrm{v}}=2.92 \mathrm{eV}, E\left(\mathrm{~T}_{1}\right)_{\mathrm{a}}=2.49 \mathrm{eV}$, and $E\left(S_{1}\right)_{\mathrm{v}}=4.19 \mathrm{eV}$, while the second fulvene with $\mathrm{X}=\mathrm{CN}$ and $\mathrm{Y}$ $=\mathrm{NH}_{2}$ has a triplet ground $\left(\mathrm{T}_{0}\right)$ state $-0.17 \mathrm{eV}$ below the lowest singlet state and $E\left(S_{1}\right)_{\mathrm{v}}=1.45 \mathrm{eV}$. Although the HOMO and LUMO each are analogous in the two compounds, there is a marked difference in the spatial distribution of LUMO that impact $K_{\mathrm{H}, \mathrm{L}}$ (Figure S1). As a consequence, $\Delta E\left(S_{1}-T_{1}\right)_{v, v}$ equals $1.66 \mathrm{eV}$ for the first of these fulvenes while $0.66 \mathrm{eV}$ for the second. The $\Delta E\left(\mathrm{~S}_{1}-\right.$ $\left.\mathrm{T}_{1}\right)_{\mathrm{v}, \mathrm{a}}$ of the two fulvenes are fortuitously very similar (1.70 and $1.62 \mathrm{eV}$, respectively), while the $\Delta E\left(\mathrm{~S}_{1}-\mathrm{T}_{1}\right)_{\mathrm{a}, \mathrm{a}}$ could not be computed as it was not possible to locate the relaxed $S_{1}$-state geometries of the fulvenes with neither TD-DFT or CASSCF.

The two fulvenes above further represent limiting cases with regard to singlet and triplet aromaticity because the first one is strongly $6 \pi$-electron Hückel-aromatic in its $S_{0}$ state (Baird- antiaromatic in $T_{1}$ and $S_{1}$ ), while the second one is $4 \pi$-electron Baird-aromatic in its $\mathrm{T}_{0}$ state (Hückel-antiaromatic in the lowest singlet state). For the fulvene with $\mathrm{X}=\mathrm{NH}_{2}$ and $\mathrm{Y}=$ $\mathrm{CN}, \operatorname{NICS}(1)_{\mathrm{zz}, \mathrm{S} 0}=-24.8 \mathrm{ppm}$ and $\operatorname{NICS}(1)_{\mathrm{zz}, \mathrm{T} 1}=23.8 \mathrm{ppm}$, while for the fulvene with $\mathrm{X}=\mathrm{CN}$ and $\mathrm{Y}=\mathrm{NH}_{2}, \mathrm{NICS}(1)_{\mathrm{zz}, \mathrm{S} 0}$ $=27.4 \mathrm{ppm}$ and $\operatorname{NICS}(1)_{\mathrm{zz}, \mathrm{T} 0}=-11.9 \mathrm{ppm}$. Noteworthy, the strongly Baird-aromatic cyclopentadienyl cation in its $\mathrm{T}_{0}$ state, ${ }^{97,78}$ representing the limiting Baird-aromatic resonance structure of a fulvene in its triplet state, ${ }^{49}$ has a $\operatorname{NICS}(1)_{\mathrm{zz}, \mathrm{T} 0}$ value of $-26.3 \mathrm{ppm}$. In its lowest singlet state, the cyclopentadienyl cation is also strongly diradical, as evidenced by a $y_{0}$ value of 0.96 . However, the fulvene with $\mathrm{X}=\mathrm{CN}$ and $\mathrm{Y}$ $=\mathrm{NH}_{2}$, having a $\mathrm{T}_{0}$ state, is not extensively diradical in its lowest singlet state $\left(y_{0}=0.09\right)$, and other fulvenes with low $E\left(\mathrm{~T}_{1}\right)$ have even lower diradical character (Table S10). This should be compared with the reported diradical characters of tetracene and pentacene $\left(y_{0}=0.28\right.$ and 0.42 , respectively). ${ }^{63}$ Thus, although increased Baird-aromatic character of the $T_{1}$ state lowers the $E\left(T_{1}\right)$ of fulvenes, it is not followed by increased diradical character of the $S_{0}$ states until one has reached fulvenes with inverted order between the lowest singlet and triplet states.

For the fulvenes in Figure 4, the changes in (anti)aromaticity when going from $S_{0}$ to $T_{1}$, as given by $\Delta$ NICS $(1)_{z z, T 1-S 0}$, correlate to a reasonable extent with $E\left(T_{1}\right)\left(R^{2}=0.82\right.$, Figure S3), similar to what we found earlier. ${ }^{49}$ However, when regarding $E\left(\mathrm{~T}_{1}\right)$ in dependence of Baird (anti)aromaticity in the $\mathrm{T}_{1}$ state $\left(\operatorname{NICS}(1)_{\mathrm{zz}, \mathrm{T} 1}\right)$ the correlation is lower $\left(R^{2}=0.68\right.$, Figure S4). It is noteworthy that fulvenes with $E\left(\mathrm{~T}_{1}\right)_{\mathrm{a}}$ in the range of $1.1-1.2 \mathrm{eV}$ have $\mathrm{NICS}(1)_{\mathrm{zz}, \mathrm{T} 1}$ values in the range of -4 to $-2 \mathrm{ppm}$, i.e., they are nonaromatic in their $\mathrm{T}_{1}$ states. In the $S_{1}$ state, we did not run NICS calculations due to computational complications, yet calculations using the MCI in the $S_{1}$ and $T_{1}$ states for selected fulvenes reveal that the two states for each of the investigated fulvenes are similarly (anti)aromatic (see Table S6).

In Figure $5 \mathrm{~A}$ and $\mathrm{B}$, we plot $E\left(\mathrm{~T}_{1}\right)_{\mathrm{v}}, E\left(\mathrm{~T}_{1}\right)_{\mathrm{a}}$, and $E\left(\mathrm{~S}_{1}\right)_{\mathrm{v}}$ against $\operatorname{NICS}(1)_{z z, S 0}$, thereby revealing that the computed $S_{0^{-}}$ state aromaticity, which is the easiest to calculate, led to good correlations. Similar correlations were also found when plotting these energies against the difference between the NICS in $T_{1}$ and $S_{0}, \Delta \operatorname{NICS}(1)_{\mathrm{zz}, \mathrm{T} 1-\mathrm{S} 0}$ (Figure S3), which should be the NICS index that best matches $E\left(\mathrm{~T}_{1}\right)$. Importantly, and in support of our hypothesis outlined above (Figures 1 and 2A), it is clear in Figure 5A that $E\left(\mathrm{~T}_{1}\right)_{\mathrm{v}}, E\left(\mathrm{~T}_{1}\right)_{a}$, and $E\left(\mathrm{~S}_{1}\right)$ vary with $\operatorname{NICS}(1)_{z z, S 0}$ in essentially identical ways. However, when plotting $\Delta E\left(\mathrm{~S}_{1}-\mathrm{T}_{1}\right)$ against $\operatorname{NICS}(1)_{\mathrm{zz}, \mathrm{S} 0}$, it is revealed that only when both $E\left(\mathrm{~S}_{1}\right)$ and $E\left(\mathrm{~T}_{1}\right)$ are vertically excited energies is there a reasonable fit with the mean average deviation $(\mathrm{MAD})$ from the least-squares fitted trendline of $0.10 \mathrm{eV}$ (Figure $5 \mathrm{C})$. Here, it is also notable that $\Delta E\left(\mathrm{~S}_{1}-\mathrm{T}_{1}\right)$ is gradually lowered as one goes to fulvenes that are $S_{0}$ antiaromatic $/ T_{1}$ aromatic, a feature explained by the shift in the spatial distribution of the HOMO and LUMO, leading to small $K_{\mathrm{H}, \mathrm{L}}$.

Now, how do these plots agree with the hypothesis presented in Figure 2? Clearly, when based on the ZHA scheme, the $2 E\left(\mathrm{~T}_{1}\right)_{\mathrm{a}}=E\left(\mathrm{~S}_{1}\right)_{\mathrm{v}}$ threshold is reached at fulvenes with $\operatorname{NICS}(1)_{\mathrm{zz}, \mathrm{SO} 0}=-13.5 \mathrm{ppm}$ (dashed line in Figure $5 \mathrm{~B}$ ), while when based on the approach with $E\left(\mathrm{~T}_{1}\right)_{\mathrm{v}}$, the threshold appears at the extrapolated value of $45.2 \mathrm{ppm}$. As the ZHA scheme exaggerates $E\left(S_{1}\right) / E\left(T_{1}\right)$ while the approach with vertically excited $E\left(T_{1}\right)$ underestimates the ratio, it can be 
A

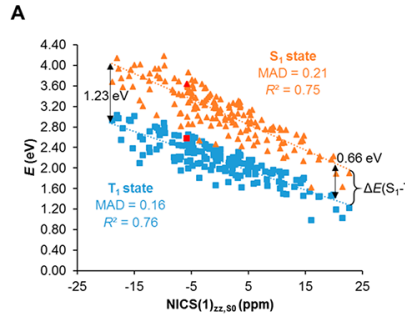

C

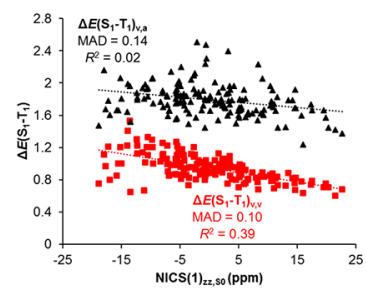

B

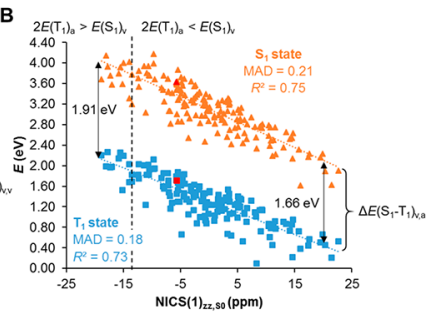

D

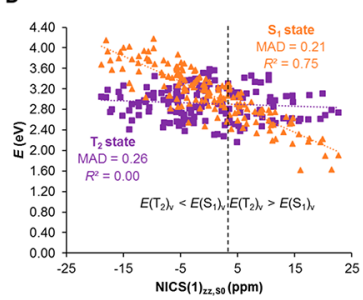

Figure 5. Plots of excited-state energies and energy differences against degree of (anti)aromaticity in $\mathrm{S}_{0}$. (A) $E\left(\mathrm{~T}_{1}\right)_{\mathrm{v}}$ and $E\left(\mathrm{~S}_{1}\right)_{\mathrm{v}}$ versus $\operatorname{NICS}(1)_{z z, S 0},(B) E\left(T_{1}\right)_{a}$ and $E\left(S_{1}\right)_{v}$ versus $\operatorname{NICS}(1)_{z z, S 0}$. (C) The energy difference between the $S_{1}$ and $T_{1}$ states versus NICS $(1)_{z z, S 0}$ (D) $E\left(\mathrm{~T}_{2}\right)_{\mathrm{v}}$ and $E\left(\mathrm{~S}_{1}\right)_{\mathrm{v}}$ versus $\operatorname{NICS}(1)_{z z, S 0}$ for tetrasubstituted fulvenes. $R^{2}$ is the squared correlation coefficient. $\operatorname{NICS}(1)_{z z, S 0}$ computed at $\mathrm{GIAO} /(\mathrm{U}) \mathrm{M} 06-2 X / 6-311+\mathrm{G}(\mathrm{d}, \mathrm{p})$ level. In (A), the parent fulvene is indicated by red marks.

concluded that the $2 E\left(\mathrm{~T}_{1}\right)=E\left(\mathrm{~S}_{1}\right)$ threshold is placed along the aromaticity coordinate represented by $\operatorname{NICS}(1)_{z Z, S 0}$. If the threshold is placed in the middle between the two limiting values then it is placed at $\operatorname{NICS}(1)_{z z, S 0}=15.8 \mathrm{ppm}$, i.e., at fulvenes that are rather strongly Hückel-antiaromatic in $S_{0}$ and Baird-aromatic in $T_{1}$.

With regard to the second threshold, $E\left(\mathrm{~S}_{1}\right)<E\left(\mathrm{~T}_{2}\right)$, it is clear in Figure $5 \mathrm{D}$ that $E\left(\mathrm{~T}_{2}\right)$ shows no correlation with $\operatorname{NICS}(1)_{z Z, S 0}\left(R^{2}=0.00\right)$. Because most substituted fulvenes have $E\left(\mathrm{~T}_{2}\right)$ in the range $2.2-3.5 \mathrm{eV}$, it is gradually more probable that the criterion $E\left(\mathrm{~S}_{1}\right)<E\left(\mathrm{~T}_{2}\right)$ is met for fulvenes with NICS $(1)_{z z, S 0}$ above $2.5 \mathrm{ppm}$, as the trendlines for $E\left(\mathrm{~T}_{2}\right)$ and $E\left(S_{1}\right)$ cross at this value. Obviously, the fulvenes with $\operatorname{NICS}(1)_{z z, S 0}$ values at $\sim 15 \mathrm{ppm}$ will also satisfy the second criterion, but their $E\left(\mathrm{~T}_{1}\right)$ will likely be far below $1 \mathrm{eV}$.

As found above, by changing the bonding or antibonding character of the HOMO and LUMO through geometric distortions (Figure 3), one can tune $E\left(\mathrm{~S}_{1}\right)$ and $E\left(\mathrm{~T}_{1}\right)$ of the parent fulvene simultaneously and similarly since the $S_{1}$ and $T_{1}$ excitations are described by the same singly excited configuration except for the spin flip. Thus, $\Delta E\left(\mathrm{~S}_{1}-\mathrm{T}_{1}\right)$ is constant along the distortion coordinate. However, $\Delta E\left(\mathrm{~S}_{1}-\right.$ $\mathrm{T}_{1}$ ) does not have the same value if one goes between differently substituted fulvenes as the spatial (de)localization of the HOMO and LUMO vary between the fulvenes. Hence, we analyzed how the $E\left(\mathrm{~T}_{1}\right)$ and $E\left(\mathrm{~S}_{1}\right)$ values change upon distortion in four substituted fulvenes in which the $\Delta E\left(\mathrm{~S}_{1}-\right.$ $\mathrm{T}_{1}$ ) values at the minimum geometry vary from 0.84 to $1.41 \mathrm{eV}$ (Figure 6). Upon distorting the $\mathrm{C} 2-\mathrm{C} 3$ bond length, the $E\left(\mathrm{~T}_{1}\right)$ and $E\left(\mathrm{~S}_{1}\right)$ values change simultaneously and similarly in three of the four fulvenes. The exception is 6,6-diaminofulvene (Figure 6B) in which the $S_{1}$ state at several of the geometries is described by a different configuration than the $\mathrm{T}_{1}$ state, revealing the importance of having the $S_{1}$ and $T_{1}$ states described by the same configuration.

The calculations show that the hypothesis on the rational tuning of $E\left(\mathrm{~T}_{1}\right)$ and $E\left(\mathrm{~S}_{1}\right)$ utilizing excited-state Baird- and
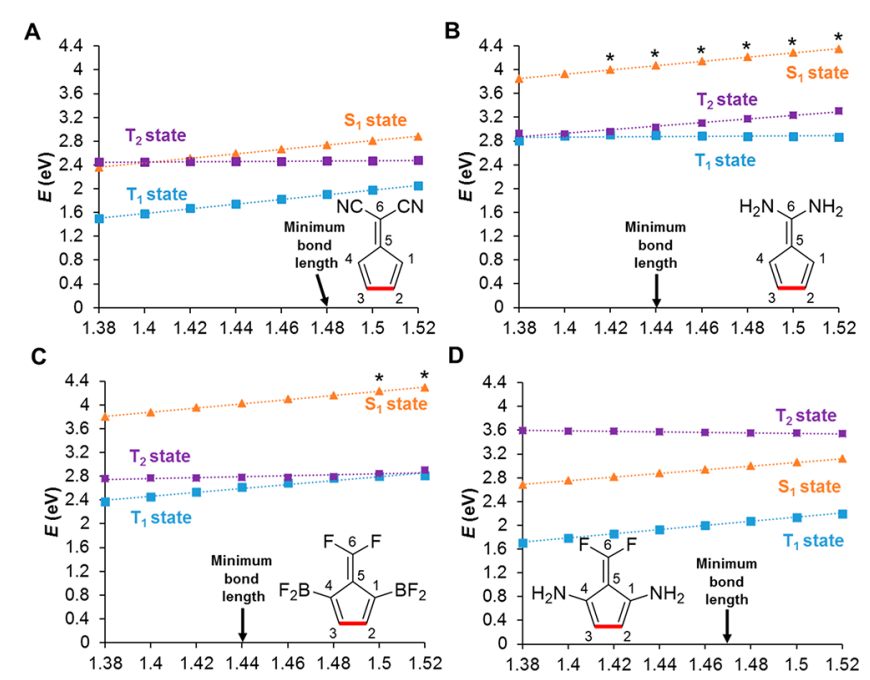

Figure 6. Variations in $E(T)_{v}, E\left(S_{1}\right)_{v}$, and $E\left(T_{2}\right)_{v}$ dependence on the $\mathrm{C} 2-\mathrm{C} 3$ bond length (red) in four fulvenes. Data points marked* correspond to other excitations than that of the singly excited HOMO-LUMO configuration of the parent fulvene.

ground-state Hückel-aromaticity is valid with TD-DFT. However, is that also the case at the CASPT2 level? The latter calculations disclose potential multireference character and whether the fulvenes exhibit double excitation character in certain excited states or not. Table S7 lists the excitations at CASPT2 and TD-M06-2X levels for a few fulvenes for which the two criteria are met (or nearly met). In short, the $E\left(\mathrm{~T}_{1}\right)$ at the CASPT2 level are similar or slightly higher $(0.2 \mathrm{eV})$ than those calculated with M06-2X. With regard to the $E\left(S_{1}\right)$, the CASPT2 energies are higher in all cases except one and sometimes $0.4 \mathrm{eV}$ higher than those at M06-2X level. For the lowest $S_{0}$ and $T_{1}$ states, the CASSCF calculations reveal one predominant configuration with a weight between 0.80 and 0.93 , revealing good agreement with $\% \mathrm{TAE}_{\mathrm{e}}([\mathrm{T}])$ (Table S9) for the first of these states. We observe that almost all of the compounds preserve the energy order of the different states and fulfill the singlet fission criteria (Table S7). The exceptions are the two model fulvenes with $\mathrm{X}=\mathrm{BF}_{2}, \mathrm{Y}=\mathrm{F}$ and with $\mathrm{X}=$ $\mathrm{CN}$ and $\mathrm{Y}=\mathrm{SiH}_{3}$. For these fulvenes, $E\left(\mathrm{~S}_{1}\right)$ and $E\left(\mathrm{~T}_{2}\right)$ are very close in energy, a feature that can lead to an $S_{1} / T_{2}$ intersystem crossing. However, one still cannot discard the possibility for singlet exciton fission because the calculated SOC for $S_{1} / T_{2}$ is merely $1.7 \mathrm{~cm}^{-1}$, i.e., $<10 \mathrm{~cm}^{-1}$, which indicates a very weak coupling, ${ }^{79}$ despite some cases with similarly small SOCs are

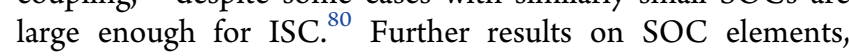
which generally are small, and $T_{1} / S_{0}$ intersystem crossing are given in the Supporting Information, yet ISC also depends on the Franck-Condon weighted density of states according to the Fermi Golden Rule, ${ }^{81}$ which is not considered in the present work.

Earlier Experimentally Investigated Fulvenes. We next considered the dicyanofulvenes (DCFs) that earlier have been synthesized by Finke et al. ${ }^{82}$ We chose to explore six of these DCFs using our strategy. The TD-M06-2X calculations using the ZHA scheme point out that these compounds could serve as singlet fission chromophores (Figure 7); however, the $S_{1}$ and $\mathrm{T}_{2}$ states are close in energy for DCIDPDCF. Importantly, the adiabatic $E\left(\mathrm{~T}_{1}\right)$ are rather close to $1 \mathrm{eV}$, despite with M06$2 \mathrm{X}$ all are below. Similarly as seen for the model fulvenes, CASPT2 gives $E\left(\mathrm{~T}_{1}\right)_{2}$, which are higher than those of M06-2X, 

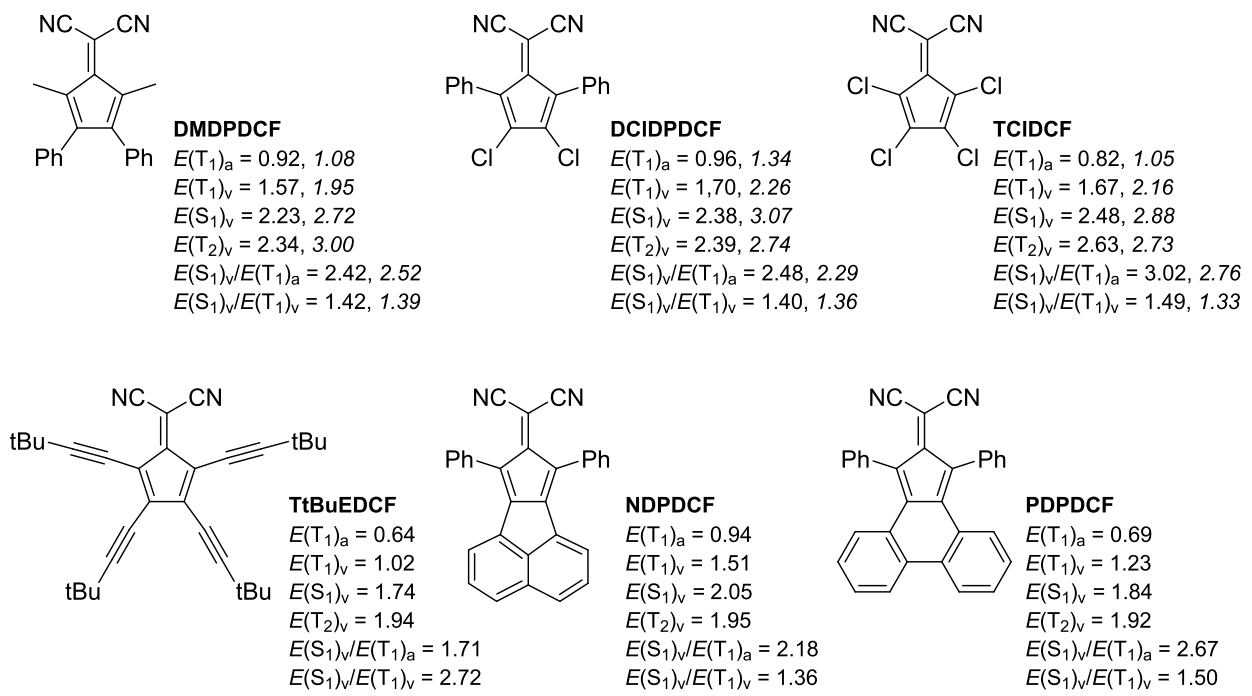

NDPDCF

$E\left(\mathrm{~T}_{1}\right)_{\mathrm{a}}=0.94$

$E\left(T_{1}\right)_{v}=1.51$

$E\left(\mathrm{~S}_{1}\right)_{\mathrm{V}}=2.05$

$E\left(\mathrm{~T}_{2}\right)_{\mathrm{v}}=1.95$

$E\left(\mathrm{~S}_{1}\right)_{\mathrm{v}} / E\left(\mathrm{~T}_{1}\right)_{\mathrm{a}}=2.18$

$E\left(\mathrm{~S}_{1}\right)_{\mathrm{V}} / E\left(\mathrm{~T}_{1}\right)_{\mathrm{V}}=1.36$

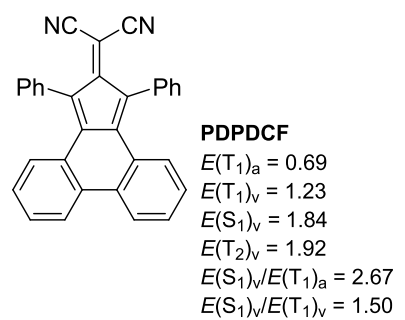

Figure 7. $\mathrm{T}_{1}, \mathrm{~S}_{1}$, and $\mathrm{T}_{2}$ energies (in eV) of six previously synthesized fulvenes computed at TD-M06-2X/def2-TZVPD//M06-2X/6-311+G(d,p) (normal print) and CASPT2(14in14)/ANO-RCC-VDZP//M06-2X/6-311+G(d,p) (italics) levels.

with $0.2-0.4 \mathrm{eV}$. In their $\mathrm{S}_{0}$ states, DCIDPDCF and TClDCF are influenced by Hückel-antiaromaticity, evident by $\operatorname{NICS}(1)_{z z, S 0}$ values of 10.1 and $23.1 \mathrm{ppm}$, respectively. On the other hand, they are nonaromatic in the $\mathrm{T}_{1}$ states, as the $\operatorname{NICS}(1)_{\mathrm{zz}, \mathrm{T} 1}$ values are -0.2 and $1.3 \mathrm{ppm}$, respectively. Substituted fulvenes and fulvenoid species, which are clearly Baird-aromatic in their $T_{1}$ states, have been designed computationally, but these have $E\left(\mathrm{~T}_{1}\right)$ which are far below 1 $\mathrm{eV}^{50}$

Interestingly, the calculated $E\left(S_{1}\right)_{\mathrm{v}} / E\left(\mathrm{~T}_{1}\right)_{\mathrm{a}}$ ratios of DCIDPDCF and TCIDCF are well above 2 , despite that they are nonaromatic in $\mathrm{T}_{1}$. The other four DCFs in Figure 7 fulfill the $E\left(S_{1}\right) / E\left(T_{1}\right)>2$ criterion, yet only three of them fulfill the $E\left(S_{1}\right)<E\left(T_{2}\right)$ criterion. The three DCFs that were also calculated at the CASPT2 level have $E\left(S_{1}\right) / E\left(\mathrm{~T}_{1}\right)$ ratios that are similar to those at the M06-2X level.

A potential caveat for fulvenes is their nonrigidity, as they can relax geometrically in the $S_{1}$ and $T_{1}$ state, making it difficult to predict their usefulness as singlet fission chromophores. Pentacene, tetracene, and DPB relax less in energy in their $T_{1}$ states compared to fulvenes (Table S8). Interestingly, from the two ratios of $E\left(\mathrm{~S}_{1}\right)_{\mathrm{v}} / E\left(\mathrm{~T}_{1}\right)_{\mathrm{v}}$ and $E\left(\mathrm{~S}_{1}\right)_{\mathrm{v}} /$ $E\left(\mathrm{~T}_{1}\right)_{\mathrm{a}}$ (Table $\mathrm{S} 8$ ), one can conclude that the relative degree of energy relaxation is smaller in the established singlet fission chromophores than in the fulvenes investigated here.

Application to Other Compound Classes. Numerous additional compound classes, which to various extents are influenced by Baird-aromaticity in their $T_{1}$ and $S_{1}$ states and have the potential to be suitable for singlet fission photovoltaics, can be listed. For that reason we explored if a similar design strategy for fulvenes can be used to identify and tailor CBDs, pentalenes, and their benzannelated derivatives as suitable singlet fission chromophores. We showed earlier that $E\left(\mathrm{~T}_{1}\right)$ of isomeric PAAHs vary with the number of aromatic monocycles in the $\mathrm{T}_{1}$ state. ${ }^{59}$ In short, the isomer with the lowest $E\left(\mathrm{~T}_{1}\right)$ has the maximum number of disjoint aromatic monocycles (one triplet diradical Baird-aromatic $\pi$-quartet $/ \pi$ octet plus closed-shell Hückel-aromatic $\pi$-sextets). In other words, it is described by Clar's rule ${ }^{56-58}$ in an extended version that incorporates Baird's $4 n$ rule. ${ }^{59}$ Provided the $S_{1}$ state is influenced similarly as the $T_{1}$ state, we argue that the benzannelation approach can be used to identify new singlet fission chromophores since $E\left(\mathrm{~T}_{1}\right)$ and $E\left(\mathrm{~S}_{1}\right)$ will be changed in energy by comparable amounts ( $c f$. Figure 1$)$.

The parent CBD has the correct arrangement of its $T_{1}, S_{1}$, and $\mathrm{T}_{2}$ states for singlet fission $\left(E\left(\mathrm{~T}_{1}\right)=0.51, E\left(\mathrm{~S}_{1}\right)=2.70\right.$ and $E\left(\mathrm{~T}_{2}\right)=4.69 \mathrm{eV}$ with M06-2X, Figure 8). However, it is

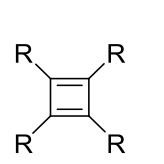

$\mathrm{R}=\mathrm{H}(\mathbf{C B D})$
$E\left(\mathrm{~T}_{1}\right)_{\mathrm{a}}=0.51$
$E\left(\mathrm{~S}_{1}\right)_{\mathrm{V}}=2.70$
$E\left(\mathrm{~T}_{2}\right)_{\mathrm{V}}=4.69$

$E\left(T_{2}\right)_{V}=4.69$

$E\left(\mathrm{~S}_{1}\right)_{\mathrm{v}} / E\left(\mathrm{~T}_{1}\right)_{\mathrm{a}}=5.29$

$\mathrm{R}={ }^{\mathrm{t} B u}$ (SCBD1) $\mathrm{R}=\mathrm{SiMe}_{3}$ (SCBD2)

$E\left(\mathrm{~T}_{1}\right)_{\mathrm{a}}=0.37 \quad E\left(\mathrm{~T}_{1}\right)_{\mathrm{a}}=0.32$

$E\left(\mathrm{~S}_{1}\right)_{\mathrm{v}}=2.56 \quad E\left(\mathrm{~S}_{1}\right)_{\mathrm{v}}=2.10$

$E\left(\mathrm{~T}_{2}\right)_{\mathrm{v}}=3.26 \quad E\left(\mathrm{~T}_{2}\right)_{\mathrm{v}}=3.64$

$E\left(\mathrm{~S}_{1}\right)_{\mathrm{v}} / E\left(\mathrm{~T}_{1}\right)_{\mathrm{a}}=6.92 \quad E\left(\mathrm{~S}_{1}\right)_{\mathrm{v}} / E\left(\mathrm{~T}_{1}\right)_{\mathrm{a}}=6.56$

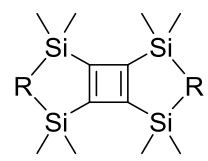

$\begin{array}{ll}\mathrm{R}=-\mathrm{CH}_{2} \mathrm{CH}_{2^{-}}(\mathbf{S C B D}) & \mathrm{R}=-\mathrm{CH}_{2^{-}}(\mathbf{S C B D 4}) \\ E\left(\mathrm{~T}_{1}\right)_{\mathrm{a}}=0.53 & E\left(\mathrm{~T}_{1}\right)_{\mathrm{a}}=0.74 \\ E\left(\mathrm{~S}_{1}\right)_{\mathrm{v}}=2.42 & E\left(\mathrm{~S}_{1}\right)_{\mathrm{v}}=2.62 \\ E\left(\mathrm{~T}_{2}\right)_{\mathrm{v}}=3.28 & E\left(\mathrm{~T}_{2}\right)_{\mathrm{v}}=2.93 \\ E\left(\mathrm{~S}_{1}\right)_{\mathrm{v}} / E\left(\mathrm{~T}_{1}\right)_{\mathrm{a}}=4.57 & E\left(\mathrm{~S}_{1}\right)_{\mathrm{v}} / E\left(\mathrm{~T}_{1}\right)_{\mathrm{a}}=3.54\end{array}$

Figure 8. Parent and substituted cyclobutadienes and their excitation energies (in eV) computed at TD-M06-2X/def2-TZVPD//M06-2X/ $6-311+\mathrm{G}(\mathrm{d}, \mathrm{p})$ level.

exceedingly unstable, and $E\left(\mathrm{~T}_{1}\right)$ is too low. Instead, three substituted CBDs (SCBD1-SCBD3), which are persistent at room temperature, ${ }^{83,84}$ were explored. Additionally, we probed an experimentally unexplored silyl-substituted CBD (SCBD4) with a more suitable energy level arrangement than the three persistent CBDs. All four substituted CBDs fulfill the fundamental singlet fission criteria, except the $E\left(\mathrm{~T}_{1}\right)$ of each one is too low.

For the three tetrasilyl-substituted CBDs (SCBD2SCBD4), there is a correlation $\left(R^{2}=0.97\right)$ between $E\left(\mathrm{~T}_{1}\right)_{\mathrm{a}}$ and the difference in aromaticity between $S_{0}$ and $T_{1}$, as 
measured by $\Delta \mathrm{NICS}(1)_{\mathrm{zz} \text { T1-S0 }}$ (Figure S7). However, the CBD with $t \mathrm{Bu}$ substituents (SCBD1) does not correlate with them, revealing that both electronic and geometric factors contribute to the $E\left(\mathrm{~T}_{1}\right)_{\mathrm{a}}$ of substituted CBDs. Moreover, in the silylsubstituted CBDs, the $T_{1}$ and $S_{1}$ states follow similar trends (Figure S7) because the $E\left(\mathrm{~T}_{1}\right)_{\mathrm{a}}$ of SCBD3 and SCBD4 increases by 0.21 and $0.42 \mathrm{eV}$ when compared to the $E\left(\mathrm{~T}_{1}\right)_{\mathrm{a}}$ of SCBD2, while $E\left(S_{1}\right)_{\mathrm{v}}$ increases by 0.32 and $0.52 \mathrm{eV}$, respectively. In contrast, the $E\left(\mathrm{~T}_{2}\right)_{\mathrm{v}}$ of SCBD3 and SCBD4, within the ZHA scheme, is lower in energy by 0.34 and 0.71 $\mathrm{eV}$, respectively, when compared to that of SCBD2.

Pentalenes as $8 \pi$-electron compounds were examined next, and in the Supporting Information, we also discuss results for indacenes being $12 \pi$-electron compounds. In particular, we looked at substituents that induce geometry changes to see if they alter the $E\left(\mathrm{~T}_{1}\right)_{a}, E\left(\mathrm{~S}_{1}\right)_{\mathrm{v}}$, and $E\left(\mathrm{~T}_{2}\right)_{\mathrm{v}}$ to any significant extents (Figure 9). Pentalenes are strongly $\mathrm{T}_{1}$-state Baird-<smiles>[R]C1=CC2=C([R])C([R])=CC2=C1[R]</smiles>

$\begin{array}{ll}\mathrm{R}=\mathrm{H}(\mathrm{PENT}) & \mathrm{R}=\mathrm{Me} \text { (SPENT1) } \\ E\left(\mathrm{~T}_{1}\right)_{\mathrm{a}}=0.63 & E\left(\mathrm{~T}_{1}\right)_{\mathrm{a}}=0.60 \\ E\left(\mathrm{~S}_{1}\right)_{\mathrm{v}}=1.89 & E\left(\mathrm{~S}_{1}\right)_{\mathrm{v}}=1.93 \\ E\left(\mathrm{~T}_{2}\right)_{\mathrm{v}}=1.75 & E\left(\mathrm{~T}_{2}\right)_{\mathrm{v}}=2.11 \\ E\left(\mathrm{~S}_{1}\right)_{\mathrm{v}} / E\left(\mathrm{~T}_{1}\right)_{\mathrm{a}}=3.00 & E\left(\mathrm{~S}_{1}\right)_{\mathrm{v}} / E\left(\mathrm{~T}_{1}\right)_{\mathrm{a}}=3.22 \\ & \\ & \\ \mathrm{R}=t \mathrm{Bu}(\mathrm{SPENT} 2) & \mathrm{R}=\mathrm{Ph}(\mathrm{SPENT} 3) \\ E\left(\mathrm{~T}_{1}\right)_{\mathrm{a}}=0.66 & E\left(\mathrm{~T}_{1}\right)_{\mathrm{a}}=0.48 \\ E\left(\mathrm{~S}_{1}\right)_{\mathrm{v}}=1.88 & E\left(\mathrm{~S}_{1}\right)_{\mathrm{v}}=1.55 \\ E\left(\mathrm{~T}_{2}\right)_{\mathrm{v}}=1.92 & E\left(\mathrm{~T}_{2}\right)_{\mathrm{v}}=1.69 \\ E\left(\mathrm{~S}_{1}\right)_{\mathrm{v}} / E\left(\mathrm{~T}_{1}\right)_{\mathrm{a}}=2.85 & E\left(\mathrm{~S}_{1}\right)_{\mathrm{v}} / E\left(\mathrm{~T}_{1}\right)_{\mathrm{a}}=3.22\end{array}$

Figure 9. Parent and substituted pentalenes and their excitation energies (in eV) computed at the TD-M06-2X/def2-TZVPD//M06$2 X / 6-311+G(\mathrm{~d}, \mathrm{p})$ level.

aromatic, ${ }^{59}$ but according to our calculations, the parent compound only satisfies the $2 E\left(\mathrm{~T}_{1}\right)_{\mathrm{a}}<E\left(\mathrm{~S}_{1}\right)_{\mathrm{v}}$ criterion. Two further drawbacks are the calculated $E\left(\mathrm{~T}_{1}\right)_{\mathrm{a}}$ of $\sim 0.6 \mathrm{eV}$ and the exceptionally low stability of the parent pentalene; however, persistent substituted pentalenes have been reported. ${ }^{85,86}$ One could argue that substituents can tune $E\left(\mathrm{~T}_{1}\right)$ because the HOMO and LUMO have opposing nodal features at the formal $\mathrm{C}-\mathrm{C}$ single bonds. However, substituents at the 1,2and 4,5-positions change $E\left(T_{1}\right)_{a}$ minutely, even when they are bulky. Rewardingly, the singlet fission criteria according to the ZHA scheme are satisfied for all three substituted pentalenes.

Because CBD has the correct state ordering while benzene does not (Figure 1), it should be possible to tailor compounds with the proper ordering of $E\left(\mathrm{~T}_{1}\right), E\left(\mathrm{~S}_{1}\right)$, and $E\left(\mathrm{~T}_{2}\right)$ through fusion of benzene and $\mathrm{CBD}$ rings in certain proportions and with certain connectivities. That said, how should CBD optimally be benzannelated to arrive at suitable singlet fission chromophores? Also, can sterically congestive substituents alter the excited-state energy levels of the larger benzannelated CBD compounds? A selection of benzannelated CBDs were examined (Figure 10). The same reasoning and questions were applied to pentalenes (vide infra).

Indeed, fusion of one $\mathrm{CBD}$ and one benzene ring into benzocyclobutadiene (BENZCBD1) yields a compound that, according to computations, has the correct state ordering for singlet fission. The calculated $E\left(\mathrm{~T}_{1}\right)_{\mathrm{a}}$ is slightly higher than ideal, yet BENZCBD1 is still a highly reactive species and may also, as a result of the small CBD ring, decay nonradiatively to the $S_{0}$ state. Among the three isomers with one CBD and two benzene rings, only one isomer satisfies the two singlet fission criteria: BENZCBD2. Using the extended version of Clar's rule, ${ }^{59}$ it becomes clear that this isomer is the only isomer among the three that can be described by two aromatic monocycles in its $\mathrm{T}_{1}$ state: one triplet diradical Baird-aromatic $\pi$-quartet and one closed-shell Hückel-aromatic $\pi$-sextet (see Figure S19 for ACID plots). ${ }^{59}$ In the $S_{0}$ state, it is notable that the diradical character increases somewhat when going from BENZCBD1 $\left(y_{0}=0.11\right.$, Table S10) to BENZCBD2 $\left(y_{0}=\right.$ $0.23)$.

An interesting aspect of the $E\left(\mathrm{~T}_{1}\right)_{\mathrm{a}}, E\left(\mathrm{~S}_{1}\right)_{\mathrm{v}}$, and $E\left(\mathrm{~T}_{2}\right)_{\mathrm{v}}$ of the two naphtoCBDs is the fact that when going from BENZCBD2 to BENZCBD3 the $T_{1}$ and $S_{1}$ states increase in energy by near-identical amounts $(0.86$ and $0.84 \mathrm{eV}$, respectively), while the $T_{2}$ state goes up by much less $(0.18$ $\mathrm{eV})$. This suggests that the $T_{1}$ and $S_{1}$ states in the two compounds are described by the same electron configuration (except for the multiplicity), following Figure 1. Indeed, according to TD-DFT computations, the $S_{1}$ states of both compounds are singly excited HOMO $\rightarrow$ LUMO excitations (see Table S18). Here, it can be noted that when increasing the molecular size from BENZCBD1 to the dibenzannelated BENZCBD2-BENZCBD4, the energy differences between the vertical and adiabatic excited-state energies decrease, both in $\mathrm{T}_{1}$ and $\mathrm{S}_{1}$ (Table S26).

One can tune $E\left(\mathrm{~T}_{1}\right)$ and $E\left(\mathrm{~S}_{1}\right)$ in two ways: through benzannelation and through $\mathrm{C}-\mathrm{C}$ bond length distortions (or generally, geometric contortions). ${ }^{55}$ As seen below, the first provides for larger tunings of the excited-state energies of PAAHs because $\mathrm{C}-\mathrm{C}$ bond length distortions in BENZCBD2, a small PAAH, lead to variations in $E\left(\mathrm{~T}_{1}\right)$ and $E\left(\mathrm{~S}_{1}\right)$ in the range of $0.1-0.2 \mathrm{eV}$ (see Figure $\mathrm{S} 15$ ). In larger benzannelated PAAHs, where HOMO and LUMO are delocalized over further atoms, the energy tunings will be even smaller. Tuning through benzannelation should therefore be the preferred means to broadly identify PAAHs that satisfy the singlet fission criteria, while bond length changes provide fine-tuning of $E\left(\mathrm{~T}_{1}\right)$ and $E\left(\mathrm{~S}_{1}\right)$. When fusing a benzene ring onto BENZCBD2, leading to BENZCBD5, the $T_{1}$ and $S_{1}$ states are lowered in energy by 0.24 and $0.22 \mathrm{eV}$, respectively, while the $\mathrm{T}_{2}$ state increases by $0.10 \mathrm{eV}$. Thus, $E\left(\mathrm{~S}_{1}\right)_{\mathrm{v}}$ follows the pattern of $E\left(T_{1}\right)_{a}$ when going from BENZCBD2 to BENZCBD5, in line with the hypothesis outlined in Figure 1 providing a general means for singlet fission chromophore design. Indeed, with BENZCBD5, we identify a PAAH that satisfies the two singlet fission criteria; however, it is a truly unstable compound ${ }^{87}$ with some diradical character in $S_{0}\left(y_{0}=\right.$ $0.28)$.

Several interesting patterns emerge when going to more extensively benzannelated CBDs. Benzobiphenylene (BENZCBD6), when compared to biphenylene (BENZCBD4), has $E\left(\mathrm{~T}_{1}\right)$ and $E\left(\mathrm{~S}_{1}\right)$, which are lower by 0.52 and $0.56 \mathrm{eV}$, respectively, while $E\left(\mathrm{~T}_{2}\right)$ is lower by $0.30 \mathrm{eV}$. Hence, the $E\left(S_{1}\right)_{\mathrm{v}} / E\left(\mathrm{~T}_{1}\right)_{\mathrm{a}}$ ratio upon fusion of one benzene ring onto biphenylene in an angular manner increases from 1.57 to 1.73 , while extending in a linear way to BENZPENT7 lowers it to 1.32. Further angular benzannelation to transdinaphthoCBD (BENZCBD9) brings $E\left(\mathrm{~T}_{1}\right)_{\mathrm{a}}$ well below 


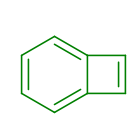

BENZCBD1

$E\left(T_{1}\right)_{a}=1.45,1.37$ $E\left(\mathrm{~S}_{1}\right)_{\mathrm{V}}=3.14,3.48$ $E\left(T_{2}\right)_{v}=4.24,4.07$ $E\left(\mathrm{~S}_{1}\right)_{\mathrm{V}} / E\left(\mathrm{~T}_{1}\right)_{\mathrm{a}}=2.17,2.54 \quad E\left(\mathrm{~S}_{1}\right)_{\mathrm{v}} / E\left(\mathrm{~T}_{1}\right)_{\mathrm{a}}=2.62,2.79$

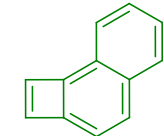

BENZCBD2

$E\left(T_{1}\right)_{a}=0.98,1.00$

$E\left(\mathrm{~S}_{1}\right)_{\mathrm{v}}=2.57,2.79$

$E\left(\mathrm{~T}_{2}\right)_{\mathrm{V}}=3.35,3.38$

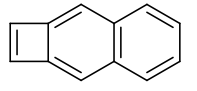

BENZCBD3

$E\left(T_{1}\right)_{a}=1.84,1.70$

$E\left(\mathrm{~S}_{1}\right)_{\mathrm{v}}=3.41,3.71$

$E\left(\mathrm{~T}_{2}\right)_{\mathrm{v}}=3.53,3.60$

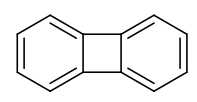

BENZCBD4

$E\left(\mathrm{~T}_{1}\right)_{\mathrm{a}}=2.28,2.16$

$E\left(\mathrm{~S}_{1}\right)_{\mathrm{V}}=3.59,3.70$

$E\left(\mathrm{~T}_{2}\right)_{\mathrm{v}}=3.67,3.84$

$E\left(\mathrm{~S}_{1}\right)_{\mathrm{v}} / E\left(\mathrm{~T}_{1}\right)_{\mathrm{a}}=1.57,1.71$

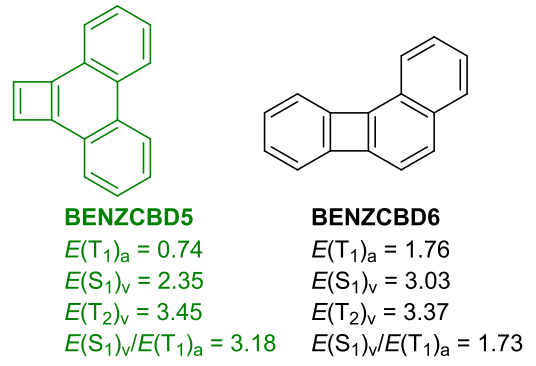

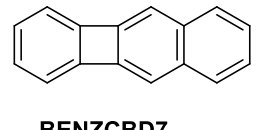

BENZCBD7

$E\left(\mathrm{~T}_{1}\right)_{\mathrm{a}}=2.96$

$E\left(\mathrm{~S}_{1}\right)_{\mathrm{v}}=3.90$ *

$E\left(\mathrm{~T}_{2}\right)_{\mathrm{V}}=3.10$

$E\left(\mathrm{~S}_{1}\right)_{\mathrm{v}} / E\left(\mathrm{~T}_{1}\right)_{\mathrm{a}}=1.32$
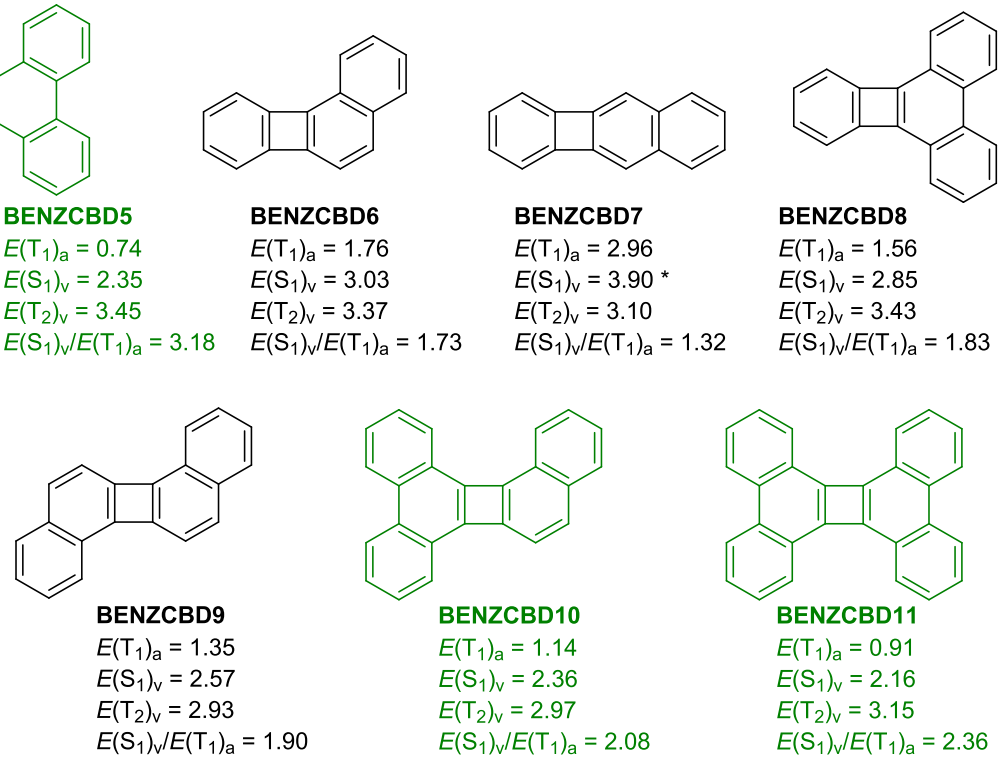

Figure 10. Benzannelated cyclobutadiene compounds and their excitation energies (in eV) computed at TD-M06-2X/def2-TZVPD//M06-2X/6$311+\mathrm{G}(\mathrm{d}, \mathrm{p})$ and CASPT2/ANO-RCC-VDZP//CASSCF $(n, m) /$ ANO-RCC-VDZP (italics, $n=m=8$ for BENZCBD1 and $n=m=12$, for BENZCBD2) levels. The compounds for which both singlet fission criteria are satisfied are marked in green. For full compound names, see Figure S20.

$E\left(S_{1}\right)_{v}$, but the $E\left(S_{1}\right)_{v} / E\left(T_{1}\right)_{a}$ ratio is still smaller than 2 . Here, it should be noted that the connectivity is crucial because BENZCBD9 has a higher $E\left(S_{1}\right)_{\mathrm{v}} / E\left(\mathrm{~T}_{1}\right)_{\mathrm{a}}$ ratio than the isomeric $\mathrm{BENZCBD8}$. Going to the penta- and hexabenzannelated CBDs, BENZCBD10 and BENZCBD11, both singlet fission criteria become satisfied within the $\mathrm{ZHA}$ scheme. According to M06-2X, the first of these compounds has $E\left(\mathrm{~T}_{1}\right)_{\mathrm{a}}$ in the ideal energy range. Another feature of importance is the oscillator strengths for transitions to $S_{1}$ in the benzannelated CBDs, which are suitable for singlet fission. Indeed, transitions to this state are weakly allowed in BENZCBD5, BENZCBD7, and BENZCBD8 (Table S19), and one of these compounds (BENZCBD5) is in theory interesting for singlet fission.

The Baird-aromatic character of a benzannelated $4 n \pi$ electron compound in its $T_{1}$ state increases with the possibility to form local aromatic monocycles (one Baird- and several Hückel-aromatic ones). ${ }^{59}$ Still, the Hückel-antiaromatic character of these compounds in their $S_{0}$ states is significant, in line with an often observed low stability, and NICS-XY scans indicate that it is even accentuated in BENZCBD5 when compared to the other two (Figure 11). However, the $\mathrm{T}_{1}$-state Baird-aromaticity in the $\mathrm{CBD}$ ring in this compound is more apparent according to NICS-XY; but a weak global diatropic circuit also exists, as indicated by the ACID plot (Figure S19). Interestingly, the CBD unit in BENZCBD5 in the $\mathrm{T}_{1}$ state seems equally aromatic as in BENZCBD10 and BENZCBD11 but less aromatic to that of BENZCBD9 (Figure S17). However, the assessment of the aromaticity of the CBD ring
A
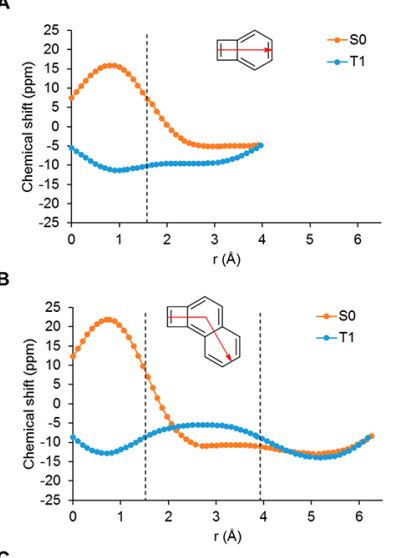

C

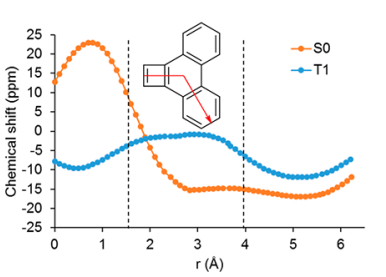

D
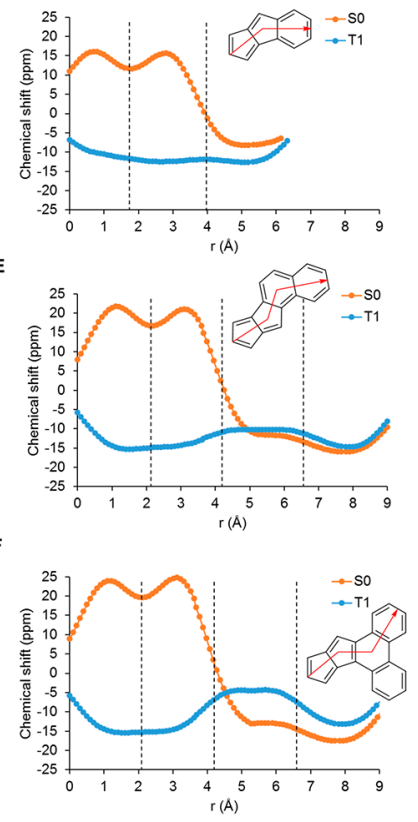

Figure 11. NICS- $X Y$ scans of (A) BENZCBD1, (B) BENZCBD2, (C) BENZCBD5, (D) BENZPENT1, (E) BENZPENT3, and (F) BENZPENT7 in their $\mathrm{S}_{0}$ and $\mathrm{T}_{1}$ states calculated at GIAO/M06-2X/ $6-311+\mathrm{G}(\mathrm{d}, \mathrm{p})$ level. 


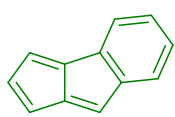

BENZPENT1

$E\left(T_{1}\right)_{\mathrm{a}}=1.04,1.08$

$E\left(\mathrm{~S}_{1}\right)_{\mathrm{v}}=2.30,2.60$

$E\left(T_{2}\right)_{V}=2.27,2.50$

$E\left(\mathrm{~S}_{1}\right)_{\mathrm{v}} / E\left(\mathrm{~T}_{1}\right)_{\mathrm{a}}=2.21,2.41$

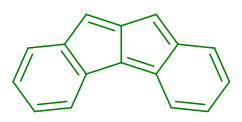

BENZPENT6

$E\left(T_{1}\right)_{\mathrm{a}}=0.12,0.28$

$E\left(\mathrm{~S}_{1}\right)_{\mathrm{v}}=1.28,1.56$

$E\left(\mathrm{~T}_{2}\right)_{\mathrm{v}}=1.48,1.99$

$E\left(\mathrm{~S}_{1}\right)_{\mathrm{v}} / E\left(\mathrm{~T}_{1}\right)_{\mathrm{a}}=10.75,5.54$

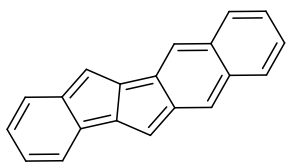

BENZPENT10

$E\left(\mathrm{~T}_{1}\right)_{\mathrm{a}}=1.76$

$E\left(\mathrm{~S}_{1}\right)_{\mathrm{V}}=2.88$ *

$E\left(\mathrm{~T}_{2}\right)_{\mathrm{V}}=2.23$

$E\left(\mathrm{~S}_{1}\right)_{\mathrm{v}} / E\left(\mathrm{~T}_{1}\right)_{\mathrm{a}}=1.63$
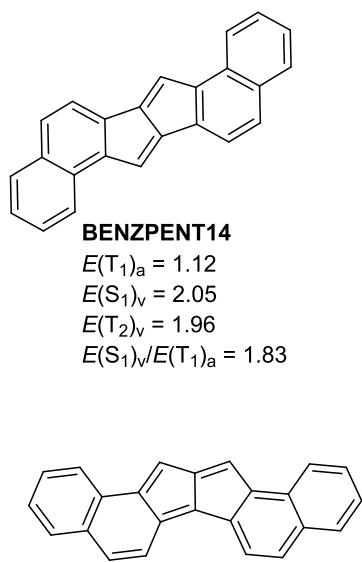

BENZPENT17

$E\left(\mathrm{~T}_{1}\right)_{\mathrm{a}}=0.39$

$E\left(S_{1}\right)_{V}=1.32$

$E\left(\mathrm{~T}_{2}\right)_{\mathrm{V}}=1.26$

$E\left(\mathrm{~S}_{1}\right)_{\mathrm{v}} / E\left(\mathrm{~T}_{1}\right)_{\mathrm{a}}=3.39$

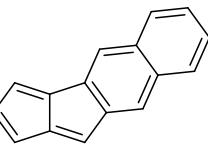

BENZPENT2

$E\left(T_{1}\right)_{a}=1.15$

$E\left(\mathrm{~S}_{1}\right)_{\mathrm{V}}=2.49$

$E\left(T_{2}\right)_{V}=2.28$

$E\left(\mathrm{~S}_{1}\right)_{\mathrm{v}} / E\left(\mathrm{~T}_{1}\right)_{\mathrm{a}}=2.16$

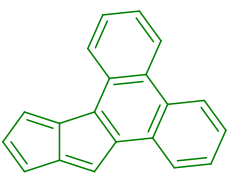

BENZPENT7

$E\left(T_{1}\right)_{a}=0.74$

$E\left(\mathrm{~S}_{1}\right)_{\mathrm{V}}=1.82$

$E\left(T_{2}\right)_{V}=2.02$

$E\left(\mathrm{~S}_{1}\right)_{\mathrm{v}} / E\left(\mathrm{~T}_{1}\right)_{\mathrm{a}}=2.49$

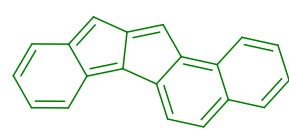

BENZPENT11

$E\left(\mathrm{~T}_{1}\right)_{\mathrm{a}}=0.51$

$E\left(\mathrm{~S}_{1}\right)_{\mathrm{V}}=1.59$

$E\left(T_{2}\right)_{v}=1.64$

$E\left(\mathrm{~S}_{1}\right)_{\mathrm{v}} / E\left(\mathrm{~T}_{1}\right)_{\mathrm{a}}=3.11$
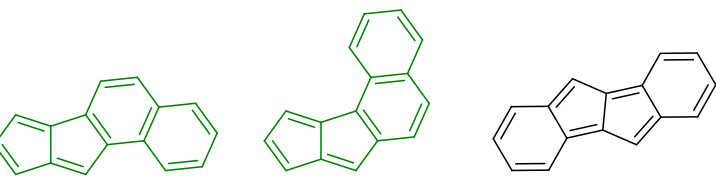

BENZPENT3

$E\left(\mathrm{~T}_{1}\right)_{\mathrm{a}}=0.86$

$E\left(S_{1}\right)_{\mathrm{V}}=1.97$

$E\left(T_{2}\right)_{V}=2.04$

$E\left(\mathrm{~S}_{1}\right)_{\mathrm{v}} / E\left(\mathrm{~T}_{1}\right)_{\mathrm{a}}=2.30$

\section{BENZPENT4}

$E\left(\mathrm{~T}_{1}\right)_{\mathrm{a}}=0.84$

$E\left(\mathrm{~S}_{1}\right)_{\mathrm{V}}=1.77$

$E\left(T_{2}\right)_{\mathrm{v}}=1.97$

$E\left(\mathrm{~S}_{1}\right)_{\mathrm{v}} / E\left(\mathrm{~T}_{1}\right)_{\mathrm{a}}=2.11$

BENZPENT5

$E\left(T_{1}\right)_{\mathrm{a}}=1.70$

$E\left(\mathrm{~S}_{1}\right)_{\mathrm{V}}=2.69$

$E\left(T_{2}\right)_{V}=2.18$

$E\left(\mathrm{~S}_{1}\right)_{\mathrm{v}} / E\left(\mathrm{~T}_{1}\right)_{\mathrm{a}}=$

1.58

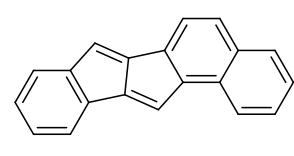

BENZPENT8

$E\left(T_{1}\right)_{a}=1.33$

$E\left(\mathrm{~S}_{1}\right)_{\mathrm{v}}=2.34$

$E\left(T_{2}\right)_{V}=2.11$

$E\left(\mathrm{~S}_{1}\right)_{\mathrm{v}} / E\left(\mathrm{~T}_{1}\right)_{\mathrm{a}}=1.76$

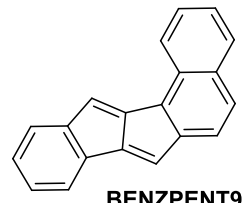

NZPENT9

$E\left(T_{1}\right)_{\mathrm{a}}=1.33$

$E\left(\mathrm{~S}_{1}\right)_{\mathrm{v}}=2.32$

$E\left(\mathrm{~T}_{2}\right)_{\mathrm{v}}=2.14$

$E\left(\mathrm{~S}_{1}\right)_{\mathrm{v}} / E\left(\mathrm{~T}_{1}\right)_{\mathrm{a}}=1.74$<smiles>C1=C2C(=Cc3ccccc32)c2c1c1ccccc1c1ccccc21</smiles>

BENZPENT12

$E\left(T_{1}\right)_{a}=1.16$

$E\left(\mathrm{~S}_{1}\right)_{\mathrm{v}}=2.18$

$E\left(\mathrm{~T}_{2}\right)_{\mathrm{v}}=2.12$

$E\left(\mathrm{~S}_{1}\right)_{\mathrm{v}} / E\left(\mathrm{~T}_{1}\right)_{\mathrm{a}}=1.88$

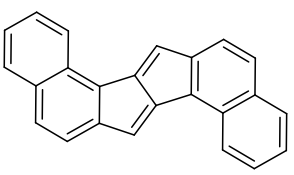

BENZPENT13

$E\left(T_{1}\right)=1.09$

$E\left(\mathrm{~S}_{1}\right)_{\mathrm{v}}=2.02$

$E\left(\mathrm{~T}_{2}\right)_{\mathrm{v}}=2.10$

$E\left(\mathrm{~S}_{1}\right)_{\mathrm{V}} / E\left(\mathrm{~T}_{1}\right)_{\mathrm{a}}=1.85$

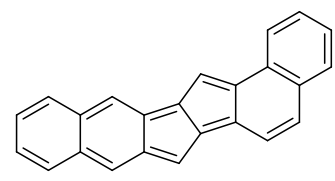

BENZPENT15

$E\left(\mathrm{~T}_{1}\right)_{\mathrm{a}}=1.42$

$E\left(\mathrm{~S}_{1}\right)_{\mathrm{V}}=2.51$

$E\left(\mathrm{~T}_{2}\right)_{\mathrm{v}}=2.15$

$E\left(\mathrm{~S}_{1}\right)_{\mathrm{v}} / E\left(\mathrm{~T}_{1}\right)_{\mathrm{a}}=1.76$

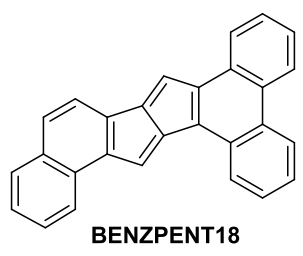

$E\left(T_{1}\right)_{a}=0.97$

$E\left(\mathrm{~S}_{1}\right)_{\mathrm{V}}=1.91$

$E\left(\mathrm{~T}_{2}\right)_{\mathrm{v}}=1.97$

$E\left(\mathrm{~S}_{1}\right)_{\mathrm{v}} / E\left(\mathrm{~T}_{1}\right)_{\mathrm{a}}=1.96$

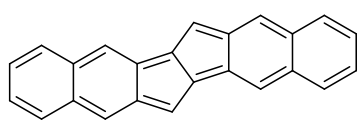

BENZPENT16

$E\left(T_{1}\right)_{a}=1.80$

$E\left(\mathrm{~S}_{1}\right)_{\mathrm{V}}=3.11$

$E\left(\mathrm{~T}_{2}\right)_{\mathrm{V}}=2.40$

$E\left(\mathrm{~S}_{1}\right)_{\mathrm{V}} / E\left(\mathrm{~T}_{1}\right)_{\mathrm{a}}=1.73$

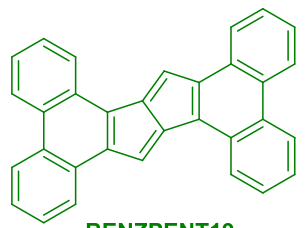

BENZPENT19

$E\left(T_{1}\right)_{a}=0.84$

$E\left(\mathrm{~S}_{1}\right)_{\mathrm{V}}=1.95$

$E\left(\mathrm{~T}_{2}\right)_{V}=2.14$

$E\left(\mathrm{~S}_{1}\right)_{\mathrm{v}} / E\left(\mathrm{~T}_{1}\right)_{\mathrm{a}}=2.32$

Figure 12. Benzannelated pentalenes and their excitation energies (in eV) computed at TD-M06-2X/def2-TZVPD//(U)M06-2X/6-311+G(d,p) (normal print) and CASPT2/ANO-RCC-VDZP//CASSCF(12,12)/ANO-RCC-VDZP (italics) levels. The compounds for which both singlet fission criteria are satisfied are marked in green. Additional benzannelated pentalenes are found in the Supporting Information. The * at the $E\left(S_{1}\right)_{\mathrm{v}}$ of BENZPENT10 indicates the two-configurational character of the $S_{1}$ state.

based on NICS is not suitable, as the NICS value in a PAAH is a composite of ring currents in several $4 n \pi$-electron circuits. HOMA, a geometry-based aromaticity index, ${ }^{73,74}$ is more suited, and it indeed shows that the aromaticity of the CBD ring in BENZCBD5 (HOMA = 0.41), which is close to that of the $\mathrm{T}_{1}$-state $\mathrm{CBD}$ (HOMA $\left.=0.45\right)$, is higher than in BENZCBD9-BENZCBD11 (HOMA $=0.13,0.21$, and 0.27, respectively). Here, it is notable that the HOMA of the $\mathrm{T}_{1}$ state of CBD is low, as the $\mathrm{C}-\mathrm{C}$ bond lengths $(1.434 \AA)$ are considerably longer than the reference value $\left(R_{\text {opt }}=1.388 \AA\right)$ that results in a HOMA of 1.0.

Similar patterns upon benzannelation to the CBDs are found for pentalenes. A drawback with pentalenes is their transitions to the $S_{1}$ state, which are forbidden or very weakly allowed (for calculated oscillator strengths, see Table S23); however, the excitation to the $S_{2}$ state in a 5,10-bis(styryl)-substituted 
dibenzo $[a, e]$ pentalene has shown to provide an entry point to singlet fission. ${ }^{88}$ The monobenzannelation in BENZPENT1 increases $E\left(T_{1}\right)$ when compared to the parent pentalene (Figure 12), similar to what was found for $\mathrm{CBD}$ and BENZCBD1, but BENZPENT1 is less ideal for singlet fission as $E\left(\mathrm{~S}_{1}\right) \approx E\left(\mathrm{~T}_{2}\right)$. On the other hand, the energy relaxation in the $S_{1}$ state, calculated as $E\left(S_{1}\right)_{v}-E\left(S_{1}\right)_{a}$, is much smaller in BENZPENT1 than in BENZCBD1 (Figure S26), and $E\left(S_{1}\right)_{a}$ / $E\left(\mathrm{~T}_{1}\right)_{\mathrm{a}}$ equals 2.06 .

With a more isolated $\mathrm{T}_{1}$-state Baird-aromatic pentalene unit, BENZPENT3 satisfies the singlet fission criteria according to the ZHA scheme but with a slightly low $E\left(\mathrm{~T}_{1}\right)$. Interestingly, dibenzo $[a, e]$ pentalene (BENZPENT5), which corresponds to the core of the compound that experimentally undergoes singlet fission when excited to $S_{2}$, satisfies none of the singlet fission criteria, yet the bis(styryl)-substitution brings down $E\left(\mathrm{~T}_{1}\right)$ whereby the experimentally explored compound fulfills the criteria (see Figure S22 for a comparison of dibenzo[a,e]pentalene with $5,10-b i s($ styryl)dibenzo $[a, e]$ pentalene). Noteworthy, the 5,10-bis(styryl) substitution introduces a new conjugation path, 1,8-diphenyl-octa-1,3,5,7-tetraene (see Figure S22), and the diradical spin density of the $T_{1}$ state is concentrated to this segment. The $S_{1}$ state, in contrast, is not lowered as much as the $T_{1}$ state, yet this state is potentially unsuitable for TD-DFT, as it is known that the $S_{1}$ state in 1,8diphenyloctatetraene has double-excitation character. ${ }^{89-91}$ Opposing dibenzo[a,e]pentalene (BENZPENT5), dibenzo$[a, f]$ pentalene (BENZPENT6), the much less stable dibenzopentalene isomer, ${ }^{92}$ satisfies both criteria, but its $E\left(\mathrm{~T}_{1}\right)$ is very low.

The $T_{1}$ and $S_{1}$ states of all benzannelated pentalenes except one are described by singly excited HOMO-LUMO excitations (the exception being BENZPENT10 with an $S_{1}$ state described as HOMO-2 $\rightarrow$ LUMO (63\%) plus HOMO $\rightarrow$ LUMO (37\%)). Thus, several trends can be observed when expanding to larger benzannelated pentalenes. However, an important feature to note in the four panels of Figure 13 is the fact that $E\left(\mathrm{~T}_{1}\right)$ and $E\left(\mathrm{~S}_{1}\right)$ follow each other closely when the benzannelation is changed. For that reason, one should compare $\Delta E\left(S_{1}-T_{1}\right)$ in a selection of compounds that follow one type of benzannelation. For example, in Figure 13A, the $\Delta E\left(\mathrm{~S}_{1}-\mathrm{T}_{1}\right)_{\mathrm{v}, \mathrm{a}}$ spans from 0.94 to $1.11 \mathrm{eV}$, while $\Delta E\left(\mathrm{~S}_{1}-\right.$ $\left.\mathrm{T}_{1}\right)_{\mathrm{v}, \mathrm{v}}$ spans from 0.39 to $0.63 \mathrm{eV}$, indicating a similar $2 K_{\mathrm{H}, \mathrm{L}}$ within the specific selection of the compound. The first trend to note is a gradual and similar lowering of $E\left(\mathrm{~T}_{1}\right)$ and $E\left(\mathrm{~S}_{1}\right)$ found when going successively from BENZPENT5 to the hexabenzannelated BENZPENT19 (Figure 13A), following the angular connectivity that maximizes the number of aromatic monocycles in $\mathrm{T}_{1} .{ }^{59}$ With BENZPENT19, a compound that has been synthesized and further investigated experimentally, ${ }^{93}$ one has reached a point where $2 E\left(\mathrm{~T}_{1}\right)<E\left(\mathrm{~S}_{1}\right)$, i.e., one is within the orange region of Figure 1. Interestingly, BENZPENT19 has very similar $E\left(\mathrm{~T}_{1}\right)_{\mathrm{a}}, E\left(\mathrm{~S}_{1}\right)_{\mathrm{v}}$ and $E\left(\mathrm{~T}_{2}\right)_{\mathrm{v}}$ values to those of BENZPENT3, and it contains four angular segments ( BENZPENT3).

When instead going from the parent pentalene to the linear dinaphtho[a,e]pentalene (BENZPENT16), both $E\left(\mathrm{~T}_{1}\right)_{\mathrm{a}}$ and $E\left(S_{1}\right)_{v}$ increase, the $E\left(S_{1}\right)_{v} / E\left(T_{1}\right)_{a}$ ratio becomes successively smaller, and $E\left(\mathrm{~T}_{2}\right)_{\mathrm{v}}$ is placed gradually further below $E\left(\mathrm{~S}_{1}\right)_{\mathrm{v}}$ (Figure 13B). Interestingly, the $\Delta E\left(S_{1}-T_{1}\right)_{\mathrm{v}, \mathrm{a}}$ of BENZPENT10, having a two-configurational $S_{1}$ state (vide supra), is smaller than that of the other four compounds in Figure 13B $(1.12$ vs $1.26-1.34 \mathrm{eV})$. The linear connectivity, which is
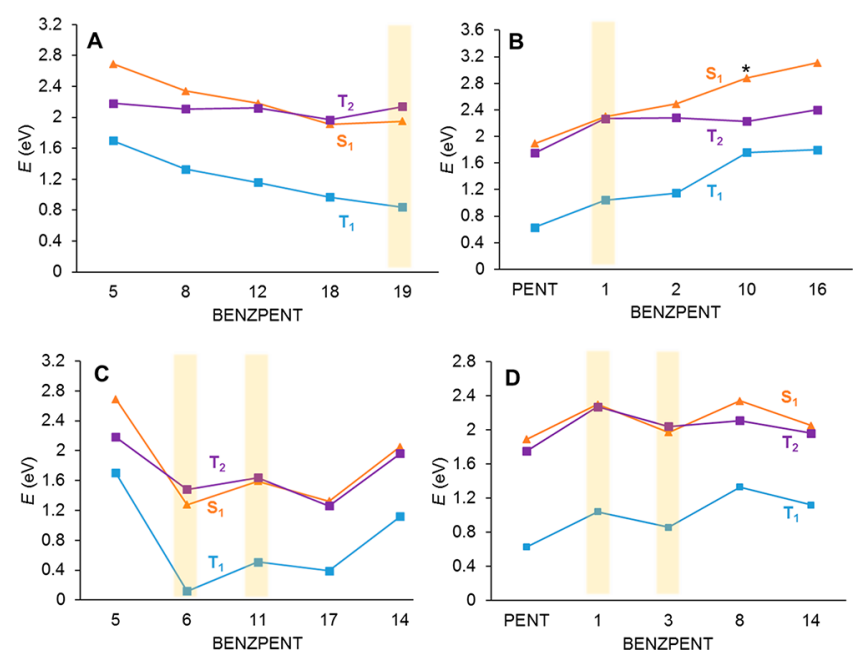

Figure 13. Variation in $E\left(\mathrm{~T}_{1}\right)_{a} E\left(\mathrm{~S}_{1}\right)_{\mathrm{v}}$, and $E\left(\mathrm{~T}_{2}\right)_{\mathrm{v}}$ calculated using the ZHA approach as a function of benzannelation in selected benzannelated pentalenes. Compounds that satisfy the singlet fission criteria are represented by yellow bars. Computations at TD-M062X/def2-TZVPD//(U)M06-2X/6-311+G(d,p) level. The * at $E\left(\mathrm{~S}_{1}\right)_{\mathrm{v}}$ of BENZPENT10 indicates the two-configurational character of the $S_{1}$ state. Further comparisons are given in Figure S23. Results of $T_{1^{-}}$ aromaticity assessments are found in Figures S25-S28.

undesirable for singlet fission chromophores, is further evidenced from the isomeric tetrabenzopentalenes BENZPENT12-BENZPENT16 (Figure S23). Also, on the basis of NICS as well as HOMA, the $T_{1}$-state aromatic character of the pentalene unit decreases when going from BENZPENT13 and BENZPENT14 to BENZPENT15 and BENZPENT16, i.e., from angular-benzannelated to linear-benzannelated compounds. In the case of BENZPENT15, we have an intermediate situation as the molecule is a combination of linear and angular connectivities. Again, the inclusion of angular-benzannelated segments leads to tuning of $E\left(S_{1}\right)$ / $E\left(\mathrm{~T}_{1}\right)$ toward higher values while linear ones do the opposite.

However, there is also another route to benzannelated pentalenes that satisfy the singlet fission criteria. Further benzannelation of dibenzo $[a, f]$ pentalene BENZPENT6 yields BENZPENT11 and BENZPENT17, which both recently were synthesized. ${ }^{94}$ The first two satisfy the singlet fission criteria (Figures 12 and $13 \mathrm{C}$ ) but with low $E\left(\mathrm{~T}_{1}\right)_{\mathrm{a}}$ values and high diradical characters $\left(y_{0}=0.48\right.$ and 0.60 , respectively). Finally, BENZPENT3 and BENZPENT7, similar to BENZCBD2 and BENZCBD5, respectively, satisfy the singlet fission criteria. Now, starting at BENZPENT3 and fusing a benzene ring or a naphthalene unit to the opposite side of the pentalene unit, one obtains benzonaphthopentalene (BENZPENT8) and trans-dinaphthopentalene (BENZPENT14), respectively, for which $E\left(\mathrm{~T}_{1}\right)_{\mathrm{a}}$ and $E\left(\mathrm{~S}_{1}\right)_{\mathrm{v}}$ increase by significant amounts and the $E\left(\mathrm{~S}_{1}\right)_{\mathrm{v}} / E\left(\mathrm{~T}_{1}\right)_{\mathrm{a}}$ ratio drops well below 2 (Figure $13 \mathrm{D}$ ). The same is found when going from BENZPENT7 to BENZPENT12, revealing that a singlet fission chromophore can be ruined by overbenzannelation. It is only when at the hexabenzannelated pentalene BENZPENT19 with four angular segments that the singlet fission criteria again are satisfied, a compound in which the $T_{1}$ state can be described with a markedly Baird-aromatic central $8 \pi$-electron pentalene moiety (HOMA $=0.75)$ and four Hückel-aromatic $6 \pi$-electron units. $^{59}$ Interestingly, when gradually building up the four angular segments going from BENZPENT8 (HOMA = 0.47), 
BENZPENT14 (HOMA $=0.67)$, and BENZPENT18 $($ HOMA $=0.70)$ to BENZPENT19, the Baird-aromatic character of the pentalene unit increases. Thus, benzannelation together with an attention to connectivity can be used to simultaneously tune $E\left(\mathrm{~T}_{1}\right)$ and $E\left(\mathrm{~S}_{1}\right)$ to similar extents such that one reaches a situation where $2 E\left(T_{1}\right)<E\left(S_{1}\right)<E\left(T_{2}\right)$.

The General Design Approach and Its Limitations. As the design approach applies to compound classes in which the extent of excited-state Baird-(anti)aromatic character varies among the individual compounds, $E\left(\mathrm{~T}_{1}\right)$ and $E\left(\mathrm{~S}_{1}\right)$ will change similarly along the aromaticity tuning coordinate, while $E\left(\mathrm{~T}_{2}\right)$ should remain more constant or change differently. The model further assumes that throughout an investigated compound class, (i) HOMO and LUMO each keep the same character ( $\sim$ symmetry), (ii) the $\mathrm{T}_{1}$ and $\mathrm{S}_{1}$ states are described by singly excited HOMO $\rightarrow$ LUMO excitations, and (iii) the spatial distributions of HOMO and LUMO are similar. The model is not applicable to compound classes in which these requirements do not hold (for example, triafulvenes, vida infra), or it is only applicable to a part of the compound class.

Information on the $E\left(\mathrm{~T}_{1}\right)$ and $\Delta E\left(\mathrm{~S}_{1}-\mathrm{T}_{1}\right)=2 K_{\mathrm{H}, \mathrm{L}}$ of the parent compound is needed for the most simple back-of-anenvelope design using the model. $A$ third parameter to consider is the slope, i.e., the extent by which $E\left(\mathrm{~T}_{1}\right)$ and $E\left(\mathrm{~S}_{1}\right)$ change in response to altered (anti)aromaticity, but a few different compounds within the compound class must be computed for this information. At the singlet fission threshold, $E\left(\mathrm{~T}_{1}\right)=\Delta E\left(\mathrm{~S}_{1}-\mathrm{T}_{1}\right)=2 K_{\mathrm{H}, \mathrm{L}}$. Thus, if the parent compounds in two compound classes have the same $E\left(\mathrm{~T}_{1}\right)$ but different $2 K_{\mathrm{H}, \mathrm{L}}$ then the compound class with the larger $2 K_{\mathrm{H}, \mathrm{L}}$ will have the threshold placed at a less $\mathrm{T}_{1}$ aromatic compound than what is the case in the compound class with a smaller $2 K_{\mathrm{H}, \mathrm{L}}$ (Figure $14 \mathrm{~A}$ and $\mathrm{B})$. A series of further situations are exemplified in
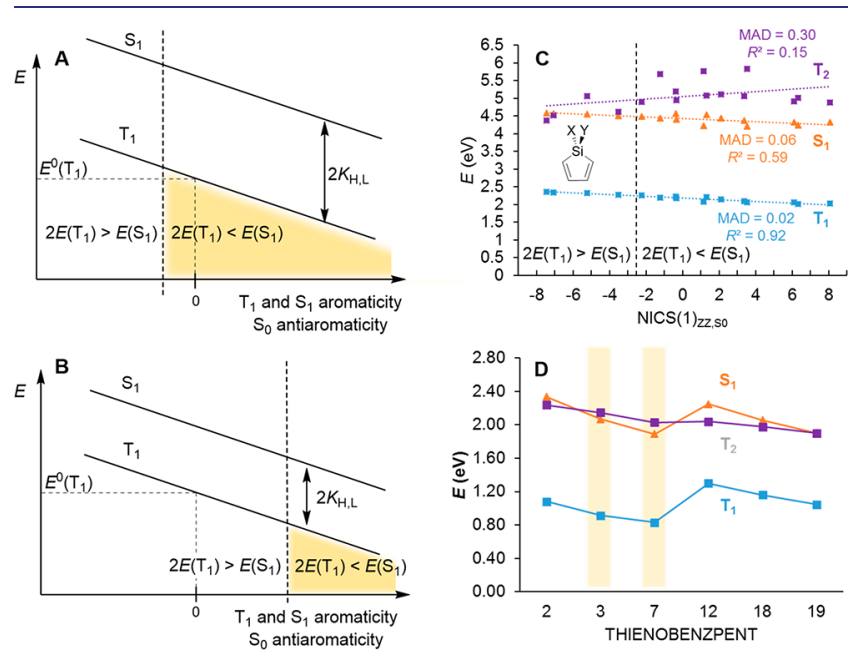

Figure 14. (A and $B)$ Schematic drawings of the changes in $E\left(T_{1}\right)$ and $E\left(S_{1}\right)$ as functions of increased $T_{1}$ and $S_{1}$ aromatic character for a compound class with (A) large $K_{\mathrm{H}, \mathrm{L}}$ and (B) small $K_{\mathrm{H}, \mathrm{L}}$. Slopes of $E\left(\mathrm{~T}_{1}\right)$ and $E\left(\mathrm{~S}_{1}\right)$ as well as the position and $E\left(\mathrm{~T}_{1}\right)$ of the parent compound (marked as 0 on the $x$-axis) are kept constant in the two plots. (C) 1,1-Disubstituted siloles with $\mathrm{X}$ and $\mathrm{Y}=\mathrm{H}, \mathrm{Me}, \mathrm{CF}_{3}, \mathrm{~F}$, $\mathrm{SiH}_{3}$, and $\mathrm{SiMe}_{3}$ as high- $E\left(\mathrm{~T}_{1}\right)$ singlet fission chromophores (for explicit energies, see Figure S33). (D) Benzannelated pentalenes where the terminal benzo rings have been exchanged for thiopheno rings (for explicit energies, see Figure S36). A comparison against the completely benzannelated pentalenes is given in the Supporting Information.
Figure S37. Here it should be noted that the additional fulfilment of the $E\left(\mathrm{~S}_{1}\right)<E\left(\mathrm{~T}_{2}\right)$ criterion may restrict the useful region, pushing it toward increased Baird-aromaticity.

The $E\left(\mathrm{~T}_{1}\right)$ of the parent compound depends on its extent of $\mathrm{T}_{1}$ aromaticity; if the parent compound is strongly (weakly) influenced by Baird-aromaticity it will have a low (high) $E\left(\mathrm{~T}_{1}\right)$. The $K_{\mathrm{H}, \mathrm{L}}$ depends on the extent of colocalization of HOMO and LUMO, as exemplified by naphthalene and azulene with $2 K_{\mathrm{H}, \mathrm{L}}$ values of 1.7 and $0.5 \mathrm{eV}$, respectively. ${ }^{44}$ Extrapolating from this observation, by strict localization of HOMO and LUMO to different atoms, one can, together with spinpolarization, design a molecule (heptazine) that has its $S_{1}$ state at a lower energy than its $\mathrm{T}_{1}$ state, ${ }^{95}$ i.e., a negative $\Delta E\left(S_{1}-\right.$ $\mathrm{T}_{1}$ ). To instead achieve a large positive $2 K_{\mathrm{H}, \mathrm{L}}$, the HOMO and LUMO should be localized to the same atoms, ideally a small number (see siloles below).

However, as noted above, $\Delta E\left(S_{1}-T_{1}\right)$ is not constant for fulvenes (Figure 5A), as it decreased for fulvenes with EWGs as exocyclic substituents, which lead to a polarization of LUMO toward the substituents, and consequently, a lowered $2 K_{\mathrm{H}, \mathrm{L}}$ and $\Delta E\left(\mathrm{~S}_{1}-\mathrm{T}_{1}\right)$. On the other hand, the model applies well to 1,1-disubstituted siloles, i.e., 1-silacyclopenta-2,4dienes, which are cross-hyperconjugated "aromatic chameleons". ${ }^{47}$ For the latter compounds, $\Delta E\left(\mathrm{~S}_{1}-\mathrm{T}_{1}\right)$ varies within the narrow interval of 2.14-2.34 eV (Figure 14C). Rewardingly, siloles may provide access to singlet fission chromophores with high $E\left(\mathrm{~T}_{1}\right)(\sim 2 \mathrm{eV})$ according to our computations, and the $2 K_{\mathrm{H}, \mathrm{L}}$ is high due to colocalizations of $\mathrm{HOMO}$ and LUMO to mainly the four $\mathrm{C}$ atoms of the diene unit (Figure S35). As siloles are already extensively explored in experiments, ${ }^{96,97}$ they may provide interesting targets as singlet fission chromophores.

Although the design approach had complications with pentafulvenes, the tria- and heptafulvenes are even more complex. The parent tria- and heptafulvenes have $E\left(\mathrm{~T}_{1}\right)$ at 2.71 and $1.41 \mathrm{eV}$, respectively, and $2 K_{\mathrm{H}, \mathrm{L}}$ at 1.87 and $1.54 \mathrm{eV}$, respectively. Thus, the parent heptafulvene, but not the triafulvene, fulfils the $2 E\left(\mathrm{~T}_{1}\right)<E\left(\mathrm{~S}_{1}\right)$ criterion. To lower $E\left(\mathrm{~T}_{1}\right)$, exocyclic electron donating substituents $\mathrm{X}$ are needed in both compound classes, ${ }^{45}$ but several substituted triafulvenes in their $T_{1}$ and $S_{1}$ states are described by other electron configurations than the singly excited HOMO $\rightarrow$ LUMO configuration that corresponds to the $T_{1}$ and $S_{1}$ states in the parent compound (see Figure S31). In heptafulvene, the $2 E\left(\mathrm{~T}_{1}\right)<E\left(\mathrm{~S}_{1}\right)$ criterion is satisfied, but one needs to step toward increased $\mathrm{T}_{1}$ aromaticity in order to achieve heptafulvenes that also satisfy the $E\left(S_{1}\right)<E\left(\mathrm{~T}_{2}\right)$ criterion. However, the $E\left(\mathrm{~T}_{1}\right)$ and $\Delta E\left(\mathrm{~S}_{1}-\mathrm{T}_{1}\right)$ values vary extensively among substituted heptafulvenes (see Figure S32 and Table S28), and their nonplanar structures in $S_{0}$ and/or $T_{1}$ are dilemma. Thus, the model also fails when large conformational changes occur within a compound class, either along the (anti)aromaticity coordinate in the $\mathrm{S}_{0}$ and/or $\mathrm{T}_{1}$ states or upon excitation.

Our design approach also applies to the benzannelated pentalenes (Figure 13). The parent pentalene is strongly Bairdaromatic in $\mathrm{T}_{1}$, and it has an $E\left(\mathrm{~T}_{1}\right)_{\mathrm{a}}$ of $0.63 \mathrm{eV}$ and $2 K_{\mathrm{H}, \mathrm{L}}$ of $1.26 \mathrm{eV}$. Thus, the singlet fission threshold should be placed at benzannelated pentalenes that are less $\mathrm{T}_{1}$ Baird-aromatic than the parent pentalene (BENZPENT3 or BENZPENT4 are computed to be close to the threshold, Figure 12). Now, as the NICS values of BENZPENT3 and BENZPENT4 are composites of $8 \pi$-, $12 \pi$ - and $16 \pi$-electron circuits, NICS is 
not a suitable method for the assessment of the $T_{1}$ aromaticity of a pentalene subunit within a benzannelated pentalene. HOMA is a better aromaticity index, and we indeed find the pentalene units in BENZPENT3 and BENZPENT4 to be less aromatic (HOMA $=0.72$ and 0.73 , respectively) than the parent pentalene $(\mathrm{HOMA}=0.86)$. The design approach also applies to thieno-annelated benzopentalenes (see Figure S36). In regard to these, they have $E\left(\mathrm{~T}_{1}\right)$ that are slightly higher than the purely benzannelated pentalenes (Figures 14D and S36), revealing the impact of the incorporation of heterocycles as a means for fine-tuning $E\left(\mathrm{~T}_{1}\right)$. Thieno-annelated benzopentalenes could be synthetically feasible, and also, these could be interesting targets for research on singlet fission photovoltaics.

\section{CONCLUSIONS}

Excited-state Baird-aromaticity in combination with Hückel ground-state aromaticity can be used in the design of singlet fission chromophores, but it is a double-edged sword. While several compounds that formally can be written with Bairdaromatic resonance structures fulfill the singlet fission criteria, the specific compound within a certain compound class that is most suitable, having an $E\left(\mathrm{~T}_{1}\right)$ of $\sim 1 \mathrm{eV}$, is not always strongly $\mathrm{T}_{1}$-state Baird-aromatic. In order to identify the compounds within a certain compound class that satisfy the singlet fission criteria and that have $E\left(\mathrm{~T}_{1}\right)$ in a suitable energy range, we have developed a general and qualitative design model.

If the $T_{1}$ and $S_{1}$ states throughout a compound class are (i) dominated by the singly excited HOMO $\rightarrow$ LUMO configuration, (ii) HOMO and LUMO each are of the same character, and (iii) distributed spatially in the same manner then the energy difference between the two states equals twice the exchange integral, $\Delta E\left(\mathrm{~S}_{1}-\mathrm{T}_{1}\right)=2 K_{\mathrm{H}, \mathrm{L}}(\mathrm{H}=\mathrm{HOMO}$ and $\mathrm{L}=\mathrm{LUMO}$ ). As a result, the relative energies of the two states are influenced by substituents (electronic or steric) and benzannelation to similar extents. With this, we develop a geometric model to identify a region along a tuning coordinate (an $\sim$ aromaticity/antiaromaticity scale or increased benzannelation), within which $2 E\left(\mathrm{~T}_{1}\right)<E\left(\mathrm{~S}_{1}\right)$ (orange region, Figure $1)$. It is noteworthy that when $E\left(T_{1}\right)$ goes below a certain threshold, the $E\left(S_{1}\right)<E\left(T_{2}\right)$ criterion generally becomes satisfied (Figures 5B and 13A). However, the model also has its limitations, the most notable being variations in $K_{\mathrm{H}, \mathrm{L}}$ and thus $\Delta E\left(\mathrm{~S}_{1}-\mathrm{T}_{1}\right)$, among individual compounds in a compound class.

Taken together, our study outlines the scope, limitations, and complications in the usage of $\mathrm{T}_{1}$-state Baird-aromaticity for the design of new singlet fission chromophores. The design approach and the qualitative (geometric) model developed provide a novel design rational. We show that through careful selection of (stable) compound classes influenced by Bairdaromaticity in $\mathrm{T}_{1}$ to various extents and with suitable $E\left(\mathrm{~T}_{1}\right)$ and $2 K_{\mathrm{H}, \mathrm{L}}$ one can tailor many new candidates for novel types of singlet fission chromophores.

\section{COMPUTATIONAL METHODS}

All $\mathrm{S}_{0^{-}}$and $\mathrm{T}_{1}$-optimized geometries were obtained using the M06-2X functional ${ }^{65}$ and $6-311+\mathrm{G}(\mathrm{d}, \mathrm{p})$ basis set. ${ }^{98}$ Additionally, for benzene and CBD, CASPT2 optimizations were carried out using the atomic natural orbital (ANO-RCC-VDZP) basis set with a contraction [B, C, N, O, F/3s2p1d, Si/4s3p2d, H/2s1p]. ${ }^{99-101}$ For vertical excitations of the substituted fulvenes, two methods were used: TD-M06-2X/def2TZVPD//M06-2X/6-311+G(d,p) and CASPT2-SA3/ANO-RCC$\mathrm{VDZP} / / \mathrm{M} 06-2 X / 6-311+\mathrm{G}(\mathrm{d}, \mathrm{p})$ at the $\mathrm{S}_{0^{-}}$or $\mathrm{T}_{1}$-optimized geo- metries. As a multiconfigurational indicator, the percentage of the perturbative triplet correction $(\mathrm{T})$ to the total $\operatorname{CCSD}(\mathrm{T})$ atomization energy $\left(\% \mathrm{TAE}_{\mathrm{e}}[(\mathrm{T})]\right)^{102}$ was evaluated at the $\operatorname{CCSD}(\mathrm{T}) /$ aug-ccpVDZ//M06-2X/6-311+G(d,p) level. Spin-orbit coupling (SOC) elements were computed within the TD-M06-2X framework using PySOC $^{80}$ DFT, TD-DFT, and $\operatorname{CCSD}(\mathrm{T})$ calculations performed using Gaussian 16 revision B.01, ${ }^{103}$ and CASPT2 computations were carried out with OpenMolcas packages. ${ }^{101}$ Aromaticity was evaluated in terms of the nucleus-independent chemical shift (NICS) ${ }^{69}$ ACID plots, ${ }^{104}$ harmonic oscillator model of aromaticity (HOMA), ${ }^{73,74}$ and multicenter index $(\mathrm{MCI})^{72}$ computed at the M06-2X/6-311+G(d,p) optimized geometries. NICS values were calculated at $1.0 \AA$ above the ring centers $\left(\operatorname{NICS}(1)_{z z}\right)^{70}$ using the gauge-independent atomic orbital (GIAO) method. ${ }^{71}$ NICS-XY scans were performed using the Aroma package, scanning from $1.7 \AA$ above the plane of the molecule. ${ }^{105}$ Distinctly negative $\operatorname{NICS}(1)_{z z}$ values indicate the aromatic character, values close to one indicate the nonaromatic character, and distinctly positive values indicate the antiaromatic character. For six PAAHs, NICS-XY scans were also computed using B3LYP- ${ }^{106}$ and CAM-B3LYP- ${ }^{107}$ optimized geometries (see Figures $\mathrm{S} 19$ and S18). MCI is an electronic index that provides a measure of electron sharing among the atoms considered: the higher the MCI value, the more aromatic the ring. MCI values were retrieved with the ESI-3D program ${ }^{108}$ using the overlaps between the occupied molecular orbitals obtained by AIMAll. ${ }^{109}$ The diradical and tetraradical character have been calculated using the spin-projected spin-unrestricted Hartree-Fock (PUHF) proposed by Yamaguchi ${ }^{110}$ (see more details in the Supporting Information).

\section{ASSOCIATED CONTENT}

\section{Supporting Information}

The Supporting Information is available free of charge at https://pubs.acs.org/doi/10.1021/jacs.9b12435.

Tables with absolute relative energies, excitation energies, aromaticity data (MCI, HOMA, $\left.\operatorname{NICS}(1)_{z z}\right)$, and diradical character. Plots of excitation energies versus HOMA and $\operatorname{NICS}(1)_{z z}$, molecular orbitals, and NICS-XY scans. List of compounds include the following: substituted fulvenes, substituted CBDs, substituted pentalenes, substituted indacenes, benzannelated CBDs, benzannelated pentalenes, triafulvenes, heptafulvenes, siloles, and thieno-benzannelated pentalenes (PDF)

\section{AUTHOR INFORMATION}

\section{Corresponding Author}

Henrik Ottosson - Department of Chemistry - Ångström Laboratory, Uppsala University, 75120 Uppsala, Sweden; () orcid.org/0000-0001-8076-1165;

Email: henrik.ottosson@kemi.uu.se

\section{Authors}

Ouissam El Bakouri - Department of Chemistry - Ångström Laboratory, Uppsala University, 75120 Uppsala, Sweden

Joshua R. Smith - Department of Chemistry - Ångström Laboratory, Uppsala University, 75120 Uppsala, Sweden; Department of Chemistry, Humboldt State University, Arcata, California 95521, United States

Complete contact information is available at:

https://pubs.acs.org/10.1021/jacs.9b12435

\section{Notes}

The authors declare no competing financial interest. 


\section{ACKNOWLEDGMENTS}

We are grateful to M. Abrahamsson and G. London for interesting discussions on the manuscript and to L. Karas, N. Proos Vedin, and J. Toldo for technical assistance. We acknowledge the Wenner-Gren Foundation for a postdoctoral fellowship of O.E.B., the Swedish Research Council (grant 2015-04538) for financial support, and the Swedish National Infrastructure for Computing via the National Supercomputer Center in Linköping, Sweden for generous allotment of computer time. J.R.S. would like to thank the Swedish Fulbright Commission, the American Scandinavian Foundation, and the HSU College of Natural Resources and Science for supporting his time at UU.

\section{REFERENCES}

(1) Shukla, A. K.; Sudhakar, K.; Baredar, P. A Comprehensive Review on Design of Building Integrated Photovoltaic System. Energy Build. 2016, 128, 99-110.

(2) Ranabhat, K.; Patrikeev, L.; Antal'evna-Revina, A.; Andrianov, K.; Lapshinsky, V.; Sofronova, E. An Introduction to Solar Cell Technology. J. Appl. Eng. Sci. 2016, 14, 481-491.

(3) Shockley, W.; Queisser, H. J. Detailed Balance Limit of Efficiency of $p-n$ Junction Solar Cells. J. Appl. Phys. 1961, 32, 510519.

(4) Nelson, C. A.; Monahan, N. R.; Zhu, X. Y. Exceeding the Shockley-Queisser Limit in Solar Energy Conversion. Energy Environ. Sci. 2013, 6, 3508.

(5) Casanova, D. Theoretical Modeling of Singlet Fission. Chem. Rev. 2018, 118, 7164-7207.

(6) Smith, M. B.; Michl, J. Singlet Fission. Chem. Rev. 2010, 110, 6891-6936.

(7) Smith, M. B.; Michl, J. Recent Advances in Singlet Fission. Annu. Rev. Phys. Chem. 2013, 64, 361-386.

(8) Japahuge, A.; Zeng, T. Theoretical Studies of Singlet Fission: Searching for Materials and Exploring Mechanisms. ChemPlusChem 2018, 83, 146-182.

(9) Wu, T. C.; Thompson, N. J.; Congreve, D. N.; Hontz, E.; Yost, S. R.; Van Voorhis, T.; Baldo, M. A. Singlet Fission Efficiency in Tetracene-Based Organic Solar Cells. Appl. Phys. Lett. 2014, 104, 193901.

(10) Einzinger, M.; Wu, T.; Kompalla, J. F.; Smith, H. L.; Perkinson, C. F.; Nienhaus, L.; Wieghold, S.; Congreve, D. N.; Kahn, A.; Bawendi, M. G.; Baldo, M. A. Sensitization of Silicon by Singlet Fission in Tetracene. Nature 2019, 571, 90-94.

(11) Kunzmann, A.; Gruber, M.; Casillas, R.; Zirzlmeier, J.; Stanzel, M.; Peukert, W.; Tykwinski, R. R.; Guldi, D. M. Singlet Fission for Photovoltaics with $130 \%$ Injection Efficiency. Angew. Chem., Int. Ed. 2018, 57, 10742-10747.

(12) Tritsch, J. R.; Chan, W.-L.; Wu, X.; Monahan, N. R.; Zhu, X.-Y. Harvesting Singlet Fission for Solar Energy Conversion via Triplet Energy Transfer. Nat. Commun. 2013, 4, 2679.

(13) Allardice, J. R.; Thampi, A.; Dowland, S.; Xiao, J.; Gray, V.; Zhang, Z.; Budden, P.; Petty, A. J., II; Davis, N. J. K. L.; Greenham, N. C.; Anthony, J. E.; Rao, A. Engineering Molecular Ligand Shells on Quantum Dots for Quantitative Harvesting of Triplet Excitons Generated by Singlet Fission. J. Am. Chem. Soc. 2019, 141, 1290712915.

(14) Pun, A. B.; Sanders, S. N.; Kumarasamy, E.; Sfeir, M. Y.; Congreve, D. N.; Campos, L. M. Triplet Harvesting from Intramolecular Singlet Fission in Polytetracene. Adv. Mater. 2017, 29, 1701416.

(15) Castrucci, J. S.; Josey, D. S.; Thibau, E.; Lu, Z.-H.; Bender, T. P. Boron Subphthalocyanines as Triplet Harvesting Materials within Organic Photovoltaics. J. Phys. Chem. Lett. 2015, 6, 3121-3125.

(16) Gish, M. K.; Pace, N. A.; Rumbles, G.; Johnson, J. C. Emerging Design Principles for Enhanced Solar Energy Utilization with Singlet Fission. J. Phys. Chem. C 2019, 123, 3923-3934.
(17) Krishnapriya, K. C.; Musser, A. J.; Patil, S. Molecular Design Strategies for Efficient Intramolecular Singlet Exciton Fission. ACS Energy Lett. 2019, 4, 192-202.

(18) Basel, B. S.; Papadopoulos, I.; Thiel, D.; Casillas, R.; Zirzlmeier, J.; Clark, T.; Guldi, D. M.; Tykwinski, R. R. Pentacenes: A Molecular Ruler for Singlet Fission. Trends in Chem. 2019, 1, 11-21.

(19) Ito, S.; Nagami, T.; Nakano, M. Molecular Design for Efficient Singlet Fission. J. Photochem. Photobiol., C 2018, 34, 85-120.

(20) Minami, T.; Ito, S.; Nakano, M. Fundamental of DiradicalCharacter-Based Molecular Design for Singlet Fission. J. Phys. Chem. Lett. 2013, 4, 2133-2137.

(21) Zeng, T.; Goel, P. Design of Small Intramolecular Singlet Fission Chromophores: An Azaborine Candidate and General Small Size Effects. J. Phys. Chem. Lett. 2016, 7, 1351-1358.

(22) Match, C.; Perkins, J.; Schreckenbach, G. Simple Computational Screening of Potential Singlet Fission Molecules. Theor. Chem. Acc. 2018, 137, 109.

(23) Nakano, M. Open-Shell-Character-Based Molecular Design Principles: Applications to Nonlinear Optics and Singlet Fission. Chem. Rec. 2017, 17, 27-62.

(24) Ito, S.; Nakano, M. Theoretical Molecular Design of Heteroacenes for Singlet Fission: Tuning the Diradical Character by Modifying $\pi$-Conjugation Length and Aromaticity. J. Phys. Chem. C 2015, 119, 148-157.

(25) Zeng, T.; Ananth, N.; Hoffmann, R. Seeking Small Molecules for Singlet Fission: A Heteroatom Substitution Strategy. J. Am. Chem. Soc. 2014, 136, 12638-12647.

(26) Ito, S.; Minami, T.; Nakano, M. Diradical Character Based Design for Singlet Fission of Condensed-Ring Systems with $4 \mathrm{n} \pi$ Electrons. J. Phys. Chem. C 2012, 116, 19729-19736.

(27) Chen, Y.; Shen, L.; Li, X. Effects of Heteroatoms of Tetracene and Pentacene Derivatives on Their Stability and Singlet Fission. J. Phys. Chem. A 2014, 118, 5700-5708.

(28) Singh, S.; Jones, W. J.; Siebrand, W.; Stoicheff, B. P.; Schneider, W. G. Laser Generation of Excitons and Fluorescence in Anthracene Crystals. J. Chem. Phys. 1965, 42, 330-342.

(29) Groff, R. P.; Avakian, P.; Merrifield, R. E. Coexistence of Exciton Fission and Fusion in Tetracene Crystals. Phys. Rev. B 1970, $1,815-817$.

(30) Burgos, J.; Pope, M.; Swenberg, Ch. E.; Alfano, R. R. Heterofission in Pentacene-Doped Tetracene Single Crystals. Phys. Status Solidi B 1977, 83, 249-256.

(31) Johnson, J. C.; Nozik, A. J.; Michl, J. High Triplet Yield from Singlet Fission in a Thin Film of 1,3-Diphenylisobenzofuran. J. Am. Chem. Soc. 2010, 132, 16302-16303.

(32) Schrauben, J. N.; Ryerson, J. L.; Michl, J.; Johnson, J. C. Mechanism of Singlet Fission in Thin Films of 1,3-Diphenylisobenzofuran. J. Am. Chem. Soc. 2014, 136, 7363-7373.

(33) Baird, N. C. Quantum organic photochemistry. II. Resonance and Aromaticity in the Lowest ${ }^{3} \pi \pi^{*}$ State of Cyclic Hydrocarbons. J. Am. Chem. Soc. 1972, 94, 4941-4948.

(34) Ottosson, H. Organic photochemistry: Exciting Excited-State Aromaticity. Nat. Chem. 2012, 4, 969-971.

(35) Rosenberg, M.; Dahlstrand, C.; Kilså, K.; Ottosson, H. Excited State Aromaticity and Antiaromaticity: Opportunities for Photophysical and Photochemical Rationalizations. Chem. Rev. 2014, 114, 5379-5425.

(36) Oh, J.; Sung, Y. M.; Hong, Y.; Kim, D. Spectroscopic Diagnosis of Excited-State Aromaticity: Capturing Electronic Structures and Conformations upon Aromaticity Reversal. Acc. Chem. Res. 2018, 51, 1349-1358.

(37) Fallon, K. J.; Budden, P.; Salvadori, E.; Ganose, A. M.; Savory, C. N.; Eyre, L.; Dowland, S.; Ai, Q.; Goodlett, S.; Risko, C.; Scanlon, D. O.; Kay, C. W. M.; Rao, A.; Friend, R. H.; Musser, A. J.; Bronstein, H. Exploiting Excited-State Aromaticity to Design Highly Stable Singlet Fission Materials. J. Am. Chem. Soc. 2019, 141, 13867-13876.

(38) Shukla, D.; Wan, P. Evidence for a Planar Cyclically Conjugated $8 \pi$ System in the Excited State: Large Stokes Shift 
Observed for Dibenz $[b, f]$ oxepin Fluorescence. J. Am. Chem. Soc. 1993, 115, 2990-2991.

(39) Toldo, J.; El Bakouri, O.; Solà, M.; Norrby, P.-O.; Ottosson, H. Is Excited-State Aromaticity a Driving Force for Planarization of Dibenzannelated $8 \pi$-Electron Heterocycles? ChemPlusChem 2019, 84, $712-721$.

(40) Ryerson, J. L.; Zaykov, A.; Aguilar Suarez, L. E.; Havenith, R. W. A.; Stepp, B. R.; Dron, P. I.; Kaleta, J.; Akdag, A.; Teat, S. J.; Magnera, T. F.; Miller, J. R.; Havlas, Z.; Broer, R.; Faraji, S.; Michl, J.; Johnson, J. C. Structure and Photophysics of Indigoids for Singlet Fission: Cibalackrot. J. Chem. Phys. 2019, 151, 184903.

(41) Ueda, M.; Jorner, K.; Sung, Y. M.; Mori, T.; Xiao, Q.; Kim, D.; Ottosson, H.; Aida, T.; Itoh, Y. Energetics of Baird Aromaticity Supported by Inversion of Photoexcited of Chiral [4n]Annulene Derivatives. Nat. Commun. 2017, 8, 346.

(42) Eckert-Maksić, M.; Vazdar, M.; Barbatti, M.; Lischka, H.; Maksić, Z. B. Automerization Reaction of Cyclobutadiene and Its Barrier Height: An Ab Initio Benchmark Multi-reference AverageQuadratic Coupled Cluster Study. J. Chem. Phys. 2006, 125, 064310.

(43) Bryce-Smith, D.; Gilbert, A. The Organic Photochemistry of Benzene - I. Tetrahedron 1976, 32, 1309-1326.

(44) Michl, J.; Thulstrup, E. W. Why is Azulene Blue and Anthracene White? A Simple MO Picture. Tetrahedron 1976, 32, 205-209.

(45) Ottosson, H.; Kilså, K.; Chajara, K.; Piqueras, M. C.; Crespo, R.; Kato, H.; Muthas, D. Scope and Limitations of Baird's Theory on Triplet State Aromaticity: Application to the Tuning of Singlet-Triplet Energy Gaps in Fulvenes. Chem. - Eur. J. 2007, 13, 6998-7005.

(46) Rosenberg, M.; Ottosson, H.; Kilså, K. Influence of Excited State Aromaticity in the Lowest Excited Singlet States of Fulvene Derivatives. Phys. Chem. Chem. Phys. 2011, 13, 12912-12919.

(47) Jorner, K.; Emanuelsson, R.; Dahlstrand, C.; Tong, H.; Denisova, A. V.; Ottosson, H. Impact of Ground and Excited State Aromaticity on Silole and Cyclopentadiene Excitation Energies and Excited State Polarities. Chem. - Eur. J. 2014, 20, 9295-9303.

(48) Yu, D.; Rong, C.; Lu, T.; De Proft, F.; Liu, S. Baird's Rule in Substituted Fulvene Derivatives: An Information-Theoretic Study on Triplet-State Aromaticity and Antiaromaticity. ACS Omega 2018, 3, 18370-18379.

(49) Yadav, S.; El Bakouri, O.; Jorner, K.; Tong, H.; Dahlstrand, C.; Solà, M.; Ottosson, H. Exploiting the Aromatic Chameleon Character of Fulvenes for Computational Design of Baird-Aromatic Triplet Ground State Compounds. Chem. - Asian J. 2019, 14, 1870-1878.

(50) Möllerstedt, H.; Crespo, R.; Piqueras, M. C.; Ottosson, H. Fulvenes, Fulvalenes, and Azulene: Are They Aromatic Chameleons? J. Am. Chem. Soc. 2004, 126, 13938-13939.

(51) Solel, E.; Kozuch, S. Tuning the Spin, Aromaticity, and Quantum Tunneling in Computationally Designed Fulvalenes. J. Org. Chem. 2018, 83, 10826-10834.

(52) Breslow, R.; Chang, H. W.; Hill, R; Wasserman, E. Stable Triplet States of Some Cyclopentadienyl Cations. J. Am. Chem. Soc. 1967, 89, 1112-1119.

(53) Breslow, R. Antiaromaticity. Acc. Chem. Res. 1973, 6, 393-398.

(54) Wörner, H. J.; Merkt, F. Photoelectron Spectroscopic Study of the First Singlet and Triplet States of the Cyclopentadienyl Cation. Angew. Chem., Int. Ed. 2006, 45, 293-296.

(55) Conrad-Burton, F. S.; Liu, T.; Geyer, F.; Costantini, R.; Schlaus, A. P.; Spencer, M. S.; Wang, J.; Sanchez, R. H.; Zhang, B.; Xu, Q.; Steigerwald, M. L.; Xiao, S.; Li, H.; Nuckolls, C. P.; Zhu, X. Controlling Singlet Fission by Molecular Contortion. J. Am. Chem. Soc. 2019, 141, 13143-13147.

(56) Clar, E. The Aromatic Sextet; Wiley: New York, 1972.

(57) Solà, M. Forty Years of Clar's Aromatic $\pi$-Sextet Rule. Front. Chem. 2013, 1, 22.

(58) El Bakouri, O.; Poater, J.; Feixas, F.; Solà, M. Exploring the Validity of the Glidewell-Lloyd Extension of Clar's $\pi$-Sextet Rule: Assessment from Polycyclic Conjugated Hydrocarbons. Theor. Chem. Acc. 2016, 135, 205.
(59) Ayub, R.; Bakouri, O. E.; Jorner, K.; Solà, M.; Ottosson, H. Can Baird's and Clar's Rules Combined Explain Triplet State Energies of Polycyclic Conjugated Hydrocarbons with Fused $4 n \pi$ - and $(4 n+2) \pi$ Rings? J. Org. Chem. 2017, 82, 6327-6340.

(60) Paci, I.; Johnson, J. C.; Chen, X.; Rana, G.; Popović, D.; David, D. E.; Nozik, A. J.; Ratner, M. A.; Michl, J. Singlet Fission for DyeSensitized Solar Cells: Can a Suitable Sensitizer Be Found? J. Am. Chem. Soc. 2006, 128, 16546-16553.

(61) Akdag, A.; Havlas, Z.; Michl, J. Search for a Small Chromophore with Efficient Singlet Fission: Biradicaloid Heterocycles. J. Am. Chem. Soc. 2012, 134, 14624-14631.

(62) Minami, T.; Nakano, M. Diradical Character View of Singlet Fission. J. Phys. Chem. Lett. 2012, 3, 145-150.

(63) Ito, S.; Nagami, T.; Nakano, M. Diradical Character-Based Design for Singlet Fission of Bisanthene Derivatives: Aromatic-Ring Attachment and $\pi$-Plane Twisting. J. Phys. Chem. Lett. 2016, 7, 3925390.

(64) Wirz, J. Electronic Structure and Photophysical Properties of Planar Conjugated Hydrocarbons with a $4 n$-Membered Ring, Part II. Jerusalem Symposia on Quantum Chemistry and Biochemistry 1977, 10, 283-294.

(65) Zhao, Y.; Truhlar, D. G. The M06 Suite of Density Functionals for Main Group Thermochemistry, Thermochemical Kinetics, Noncovalent Interactions, Excited States, and Transition Elements: Two New Functionals and Systematic Testing of Four M06-class Functionals and 12 Other Function. Theor. Chem. Acc. 2008, 120, $215-241$.

(66) Andersson, K.; Malmqvist, P.-Å.; Roos, B. O. Second-Order Perturbation Theory with a Complete Active Space Self-Consistent Field Reference Function. J. Chem. Phys. 1992, 96, 1218-1226.

(67) Zeng, T.; Hoffmann, R.; Ananth, N. The Low-Lying Electronic States of Pentacene and Their Roles in Singlet Fission. J. Am. Chem. Soc. 2014, 136, 5755-5764.

(68) Grotjahn, R.; Maier, T. M.; Michl, J.; Kaupp, M. Development of a TDDFT-Based Protocol with Local Hybrid Functionals for the Screening of Potential Singlet Fission Chromophores. J. Chem. Theory Comput. 2017, 13, 4984-4996.

(69) Schleyer, P. v. R.; Maerker, C.; Dransfeld, A.; Jiao, H.; van Eikema Hommes, N. J. R. Nucleus-Independent Chemical Shifts: A Simple and Efficient Aromaticity Probe. J. Am. Chem. Soc. 1996, 118, 6317-6318.

(70) Fallah-Bagher-Shaidaei, H.; Wannere, C. S.; Corminboeuf, C.; Puchta, R.; Schleyer, P. v. R. Which NICS Aromaticity Index for Planar $\pi$ Rings Is Best? Org. Lett. 2006, 8, 863-866.

(71) Wolinski, K.; Hinton, J. F.; Pulay, P. Efficient Implementation of the Gauge-Independent Atomic Orbital Method for NMR Chemical Shift Calculations. J. Am. Chem. Soc. 1990, 112, 8251-8260.

(72) Bultinck, P.; Rafat, M.; Ponec, R.; Van Gheluwe, B.; CarbóDorca, R.; Popelier, P. Electron Delocalization and Aromaticity in Linear Polyacenes: Atoms in Molecules Multicenter Delocalization Index. J. Phys. Chem. A 2006, 110, 7642-7648.

(73) Krygowski, T. M. Crystallographic Studies of Inter- and Intramolecular Interactions Reflected in Aromatic Character of $\pi$ Electron Systems. J. Chem. Inf. Model. 1993, 33, 70-78.

(74) Krygowski, T. M.; Cyranski, M. K. Structural Aspects of Aromaticity. Chem. Rev. 2001, 101, 1385-1419.

(75) Bearpark, M. J.; Bernardi, F.; Olivucci, M.; Robb, M. A.; Smith, B. R. Can Fulvene $S_{1}$ Decay Be Controlled? A CASSCF Study with MMVB Dynamics. J. Am. Chem. Soc. 1996, 118, 5254-5260.

(76) Mendive-Tapia, D.; Lasorne, B.; Worth, G. A.; Bearpark, M. J.; Robb, M. A. Controlling the Mechanism of Fulvene $S_{1} / S_{0}$ Decay: Switching Off the Stepwise Population Transfer. Phys. Chem. Chem. Phys. 2010, 12, 15725-15733.

(77) Gogonea, V.; Schleyer, P. v. R.; Schreiner, P. R. Consequences of Triplet Aromaticity in $4 n \pi$-Electron Annulenes: Calculation of Magnetic Shieldings for Open-Shell Species. Angew. Chem., Int. Ed. 1998, 37, 1945-1948.

(78) Villaume, S.; Fogarty, H. A.; Ottosson, H. Triplet-State Aromaticity of $4 n$-Electron Monocycles: Analysis of Bifurcation in the 
$\pi$ Contribution to the Electron Localization Function. ChemPhysChem 2008, 9, 257-264.

(79) Gao, X.; Bai, S.; Fazzi, D.; Niehaus, T.; Barbatti, M.; Thiel, W. Evaluation of Spin-Orbit Couplings with Linear-Response TimeDependent Density Functional Methods. J. Chem. Theory Comput. 2017, 13, 515-524.

(80) Samanta, P. K.; Kim, D.; Coropceanu, V.; Brédas, J. L. UpConversion Intersystem Crossing Rates in Organic Emitters for Thermally Activated Delayed Fluorescence: Impact of the Nature of Singlet vs Triplet Excited States. J. Am. Chem. Soc. 2017, 139, 40424051.

(81) Marian, C. M. Spin-Orbit Coupling and Intersystem Crossing in Molecules. Wiley Interdiscip. Rev. Comput. Mol. Sci. 2012, 2, 187203.

(82) Finke, A. D.; Jahn, B. O.; Saithalavi, A.; Dahlstrand, C.; Nauroozi, D.; Haberland, S.; Gisselbrecht, J.-P.; Boudon, C.; Mijangos, E.; Schweizer, W. B.; Ott, S.; Ottosson, H.; Diederich, F. The 6,6-Dicyanopentafulvene Core: A Template for the Design of Electron-Acceptor Compounds. Chem. - Eur. J. 2015, 21, 8168-8176.

(83) Sekiguchi, A.; Tanaka, M.; Matsuo, T.; Watanabe, H. From a Cyclobutadiene Dianion to a Cyclobutadiene: Synthesis and Structural Characterization of Tetrasilyl-Substituted Cyclobutadiene. Angew. Chem., Int. Ed. 2001, 40, 1675-1677.

(84) Maier, G.; Neudert, J.; Wolf, O. Tetrakis(Trimethylsilyl)Cyclobutadiene and Tetrakis(Trimethylsilyl)Tetrahedrane. Angew. Chem., Int. Ed. 2001, 40, 1674-1675.

(85) Hafner, K.; Süss, H. U. 1,3,5-Tri- Tert-Butylpentalene. A Stabilized Planar $8 \pi$-Electron System. Angew. Chem., Int. Ed. Engl. 1973, 12, 575-577.

(86) Levi, Z. U.; Tilley, T. D. Versatile Synthesis of Pentalene Derivatives via the Pd-Catalyzed Homocoupling of Haloenynes. J. Am. Chem. Soc. 2009, 131, 2796-2797.

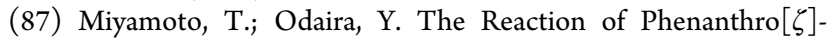
cyclobutadiene. Tetrahedron Lett. 1973, 14, 43-46.

(88) Wu, Y.; Wang, Y.; Chen, J.; Zhang, G.; Yao, J.; Zhang, D.; Fu, H. Intramolecular Singlet Fission in an Antiaromatic Polycyclic Hydrocarbon. Angew. Chem., Int. Ed. 2017, 56, 9400-9404.

(89) Hudson, B. S.; Kohler, B. E. Polyene Spectroscopy: The Lowest Energy Excited Singlet State of Diphenyloctatetraene and Other Linear Polyenes. J. Chem. Phys. 1973, 59, 4984-5002.

(90) Holtom, G. R.; McClain, W. M. Two-photon excitation spectra of the low energy excited states of diphenylhexatriene and diphenyloctatetraene. Chem. Phys. Lett. 1976, 44, 436-439.

(91) Fiedor, L.; Dudkowiak, A.; Pilch, M. The Origin of the Dark $S_{1}$ State in Carotenoids: A Comprehensive Model. J. R. Soc., Interface 2019, 16, 20190191.

(92) Baker, W.; McOmie, J. F. W.; Parfitt, S. D.; Watkins, D. A. M. 799. Attempts to Prepare New Aromatic Systems. Part VI. 1:2-5:6Dibenzopentalene and Derivatives. J. Chem. Soc. 1957, 0, 4026-4037.

(93) Oshima, H.; Fukazawa, A.; Yamaguchi, S. Facile Synthesis of Polycyclic Pentalenes with Enhanced Hückel Antiaromaticity. Angew. Chem., Int. Ed. 2017, 56, 3270-3274.

(94) Konishi, A.; Okada, Y.; Kishi, R.; Nakano, M.; Yasuda, M. Enhancement of Antiaromatic Character via Additional Benzoannulation into Dibenzo[a,f]Pentalene: Syntheses and Properties of Benzo[ $[a]$ Naphtho[2,1-f]Pentalene and Dinaphtho[2,1-a,f]Pentalene. J. Am. Chem. Soc. 2019, 141, 560-571.

(95) Ehrmaier, J.; Rabe, E. J.; Pristash, S. R.; Corp, K. L.; Schlenker, C. W.; Sobolewski, A. L.; Domcke, W. Singlet-Triplet Inversion in Heptazine and in Polymeric Carbon Nitrides. J. Phys. Chem. A 2019, 123, 8099-8108.

(96) Corey, J. Y. Siloles. Part 1: Synthesis, Characterization, and Applications. Adv. Organomet. Chem. 2011, 59, 1-180.

(97) Corey, J. Y. Siloles. Part 2: Silaindenes (Benzosiloles) and Silafluorenes Dibenzosiloles): Synthesis, Characterization, and Applications. Adv. Organomet. Chem. 2011, 59, 1-180.

(98) Krishnan, R.; Binkley, J. S.; Seeger, R.; Pople, J. A. SelfConsistent Molecular Orbital Methods. XX. A Basis Set for Correlated Wave Functions. J. Chem. Phys. 1980, 72, 650-654.
(99) Widmark, P.-O.; Persson, B. J.; Roos, B. O. Density Matrix Averaged Atomic Natural Orbital (ANO) Basis Sets for Correlated Molecular Wave Functions. Theor. Chim. Acta 1991, 79, 419-432.

(100) Andersson, K.; Malmqvist, P.-Å.; Roos, B. O. Second-Order Perturbation Theory with a Complete Active Space Self-Consistent Field Reference Function. J. Chem. Phys. 1992, 96, 1218-1226.

(101) Aquilante, F.; Autschbach, J.; Carlson, R. K.; Chibotaru, L. F.; Delcey, M. G.; De Vico, L.; Fdez Galván, I.; Ferré, N.; Frutos, L. M.; Gagliardi, L.; Garavelli, M.; Giussani, A.; Hoyer, C. E.; Li Manni, G.; Lischka, H.; Ma, D.; Malmqvist, P. Å.; Müller, T.; Nenov, A.; Olivucci, M.; Pedersen, T. B.; Peng, D.; Plasser, F.; Pritchard, B.; Reiher, M.; Rivalta, I.; Schapiro, I.; Segarra-Martí, J.; Stenrup, M.; Truhlar, D. G.; Ungur, L.; Valentini, A.; Vancoillie, S.; Veryazov, V.; Vysotskiy, V. P.; Weingart, O.; Zapata, F.; Lindh, R. Molcas 8: New Capabilities for Multiconfigurational Quantum Chemical Calculations across the Periodic Table. J. Comput. Chem. 2016, 37, 506-541.

(102) Karton, A.; Daon, S.; Martin, J. M. L. W4-11: A HighConfidence Benchmark Dataset for Computational Thermochemistry Derived from First-Principles W4 Data. Chem. Phys. Lett. 2011, 510, $165-178$.

(103) Frisch, M. J.; Trucks, G. W.; Schlegel, H. B.; Scuseria, G. E.; Robb, M. A.; Cheeseman, J. R.; Scalmani, G.; Barone, V.; Mennucci, B.; Petersson, G. A.; Nakatsuji, H.; Caricato, M.; Li, X.; Hratchian, H. P.; Izmaylov, A. F.; Bloino, J.; Zheng, G.; Sonnenberg, J. L.; Hada, M.; Ehara, M.; Toyota, K.; Fukuda, R.; Hasegawa, J.; Ishida, M.; Nakajima, T.; Honda, Y.; Kitao, O.; Nakai, H.; Vreven, T.; Montgomery, J. A., Jr.; Peralta, J. E.; Ogliaro, F.; Bearpark, M.; Heyd, J. J.; Brothers, E.; Kudin, K. N.; Staroverov, V. N.; Kobayashi, R.; Normand, J.; Raghavachari, K.; Rendell, A.; Burant, J. C.; Iyengar, S. S.; Tomasi, J.; Cossi, M.; Rega, N.; Millam, J. M.; Klene, M.; Knox, J. E.; Cross, J. B.; Bakken, V.; Adamo, C.; Jaramillo, J.; Gomperts, R.; Stratmann, R. E.; Yazyev, O.; Austin, A. J.; Cammi, R.; Pomelli, C.; Ochterski, J. W.; Martin, R. L.; Morokuma, K.; Zakrzewski, V. G.; Voth, G. A.; Salvador, P.; Dannenberg, J. J.; Dapprich, S.; Daniels, A. D.; Farkas, Ö.; Foresman, J. B.; Ortiz, J. V.; Cioslowski, J.; Fox, D. J. Gaussian 16; 2016.

(104) (a) Herges, R.; Geuenich, D. Delocalization of Electrons in Molecules. J. Phys. Chem. A 2001, 105, 3214-3220. (b) Geuenich, D.; Hess, K.; Köhler, F.; Herges, R. Anisotropy of the Induced Current Density (ACID), a General Method To Quantify and Visualize Electronic Delocalization. Chem. Rev. 2005, 105, 3758-3772.

(105) Gershoni-Poranne, R.; Stanger, A. The NICS-XY-Scan: Identification of Local and Global Ring Currents in Multi-Ring Systems. Chem. - Eur. J. 2014, 20, 5673-5688.

(106) Stephens, P. J.; Devlin, F. J.; Chabalowski, C. F.; Frisch, M. J. $\mathrm{Ab}$ Initio Calculation of Vibrational Absorption and Circular Dichroism Spectra Using Density Functional Force Fields. J. Phys. Chem. 1994, 98, 11623-11627.

(107) Yanai, T.; Tew, D. P.; Handy, N. C. A New Hybrid ExchangeCorrelation Functional Using the Coulomb-Attenuating Method (CAM-B3LYP). Chem. Phys. Lett. 2004, 393, 51-57.

(108) Matito, E. ESI-3D: Electron Sharing Indexes Program for 3D Molecular Space Partitioning; Institute of Computational Chemistry and Catalysis: Girona, Catalonia, Spain, 2006. http://iqc.udg.es/ eduard/ESI.

(109) AIMAll (Version 17.11.14 B); TK Gristmill Software: Overland Park, KS, US, 2018. http://aim.tkgristmill.com.

(110) Yamaguchi, K. Self-Consistent Field: Theory and Applications (Studies in Physical and Theoretical Chemistry); Carbo, R., Klobukoswski, M., Eds.; Elsevier Science: Amsterdam, The Netherlands, 1990; pp 727. 